\title{
Low-Frequency Surface Currents and Generation of an Island Lee Eddy in Panay Island, Philippines
}

\author{
Charina Lyn Amedo-Repollo, Xavier Flores-Vidal, ${ }^{a}$ Cedric Chavanne, ${ }^{b}$ \\ CESAR L. VillaAnOY, AND PierRe Flament ${ }^{\mathrm{c}}$
}

Marine Science Institute, University of the Philippines, Diliman, Quezon City, Philippines

(Manuscript received 19 January 2018, in final form 8 January 2019)

\begin{abstract}
High-frequency Doppler radar (HFDR) and acoustic Doppler current profiler (ADCP) time-series observations during the Philippine Straits Dynamics Experiment (PhilEx) were analyzed to describe the mesoscale currents in Panay Strait, Philippines. Low-frequency surface currents inferred from three HFDR (July 2008-July 2009), reveal a clear seasonal signal concurrent with the reversal of the Asian monsoon. A mesoscale cyclonic eddy west of Panay Island is generated during the winter northeast (NE) monsoon. This causes changes in the strength, depth, and width of the intraseasonal Panay coastal (PC) jet as its eastern limb. Winds from QuikSCAT and from a nearby airport indicate that these flow structures correlate with the strength and direction of the prevailing local wind. An intensive survey in 8-9 February 2009 using $24 \mathrm{~h}$ of successive cross-shore conductivity-temperature-depth (CTD) sections, which in conjunction with shipboard ADCP measurements, show a well-developed cyclonic eddy characterized by near-surface velocities of $50 \mathrm{~cm} \mathrm{~s}^{-1}$. This eddy coincides with the intensification of the wind in between Mindoro and Panay Islands, generating a positive wind stress curl in the lee of Panay, which in turn induces divergent surface currents. Water column response from the mean transects show a pronounced signal of upwelling, indicated by the doming of isotherms and isopycnals. A pressure gradient then is set up, resulting in the spin up of a cyclonic eddy in geostrophic balance. Evolution of the vorticity within the vortex core confirms wind stress curl as the dominant forcing.
\end{abstract}

\section{Introduction}

The mechanisms for the generation of eddies in the wake of islands are due to Ekman pumping induced by wind stress curl (Chavanne et al. 2002; Jiménez et al. 2008) and by instability of lateral shear as oceanic flow passes the island (Dong et al. 2009). The wind interaction with the island generates positive (negative) wind stress curls on the right (left) side of the island while looking downstream, causing upward (downward) Ekman pumping in the Northern Hemisphere. As oceanic flow passes an

\footnotetext{
${ }^{\text {a }}$ Current affiliation: Universitad Autonoma de Baja California, Ensenada, Mexico.

${ }^{\mathrm{b}}$ Current affiliation: Institut des Sciences de la Mer de Rimouski, Université du Québec à Rimouski, Rimouski, Canada.

${ }^{\mathrm{c}}$ Current affiliation: University of Hawai'i at Mānoa, Honolulu, Hawaii.
}

Corresponding author: Charina Lyn Amedo-Repollo, crepollo@ msi.upd.edu.ph island, horizontal shear and inhomogeneity in bottom stress induces vorticity. Thus, the lee sides of islands (headlands) tend to be areas rich in eddy activity, depending on the direction of the prevailing winds and/or oceanic currents (Lumpkin 1998; Barton et al. 2000; Chavanne et al. 2002; Calil et al. 2008; Pullen et al. 2008; Dong et al. 2009). The mixture of these two processes on lee eddy generation takes place with almost all islands, and the relative importance of these two forcing mechanisms has been assessed using numerical models and observations.

Wind forcing was identified as the trigger mechanism in the generation of Grand Canary eddies, but the main mechanism responsible for the eddy shedding was the topographic perturbation of the oceanic flow by the island flanks (Jiménez et al. 2008). An observational study by Piedeleu et al. (2009) supported this conclusion using data from a mooring leeward of Grand Canary Island. In the Hawaiian archipelago, a sensitivity study of the generation of mesoscale eddies using a numerical model suggested that the wind, current, and topography have a cumulative 


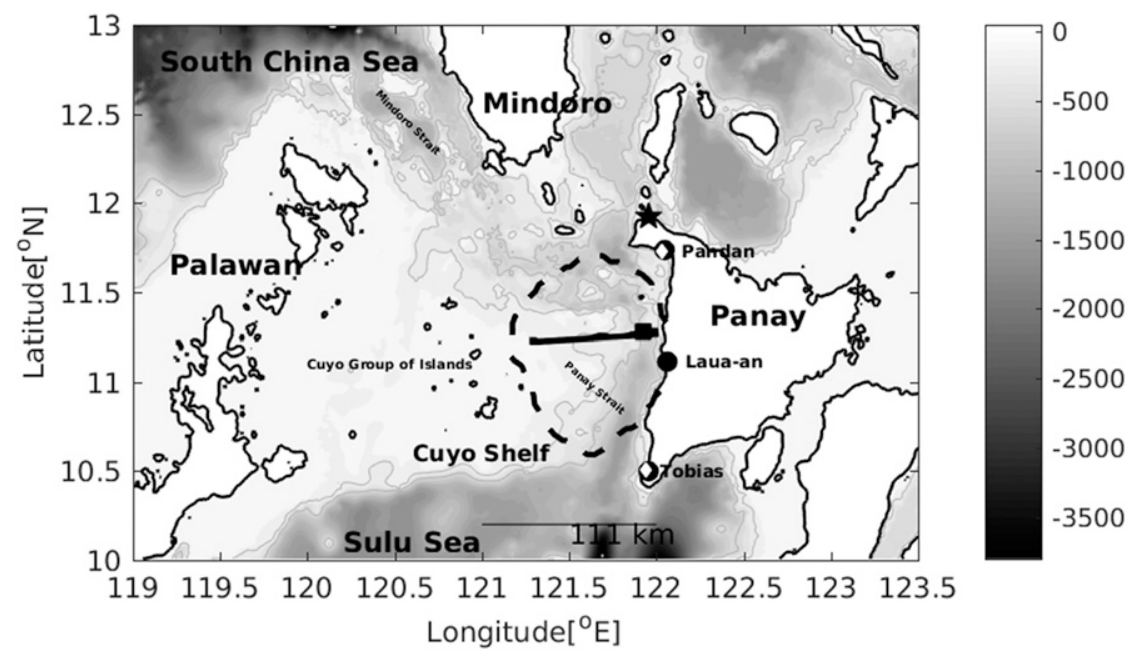

FIG. 1. Bathymetry of the study area and the limits of $75 \%$ HFDR data coverage indicated by the thick broken line. The 200-, 500-, and 1000-m isobaths are shown with increasingly darker shadings. Locations of observations are marked: HFDR by circles, shallow pressure gauges by white diamonds, ADCP by squares, TRIAXUS survey transects by solid thick lines, and the nearby Caticlan Airport by a star.

effect on the generation of eddies and the complex oceanic circulation pattern (Kersalé et al. 2011; Jia et al. 2011). However, wind forcing has been shown to substantially affect the eddy generation in the immediate lee of the islands, which clearly exhibits orographically local wind forcing as the main contributor (Calil et al. 2008; Yoshida et al. 2010; Jia et al. 2011; Kersalé et al. 2011). Further, Azevedo Correia de Souza et al. (2015) examined the ocean surface vorticity budget around the Hawaiian Islands, and this showed that the average contribution from the wind stress curl clearly indicated the influence of the islands on the trade winds. Though the interaction of the North Equatorial Current (NEC) with the major islands is enough to generate eddies, wind observations in high spatial and temporal resolution play an important role in oceanic circulation. Details of the wind shear in the lee of the islands are necessary to correctly calculate the intensities of the vorticities (Calil et al. 2008; Jia et al. 2011; Kersalé et al. 2011). For the Canary archipelago, the speed of the Canary Current is sufficient to create a flow at high-enough Reynolds number to produce eddies, but their generation was suggested to be aided through Ekman pumping by the winds in the lee region of the islands (Sangrà et al. 2009).

Without significant background currents, wind forcing in the Gulf of Tehuantepec (Barton et al. 1993; Trasviña et al. 1995) and leeward of Madeira Island (Caldeira et al. 2014) generates energetic ocean eddies through Ekman pumping. This isolates ocean response to topographically induced wind shear. The winds channeled through mountain gaps extend as a jet over the Pacific Ocean in the Gulf of
Tehuantepec and in the lee of Madeira that spin up ocean eddies. Wind-generated eddies have also been identified in the Philippines in the wake of Mindoro and Luzon Islands in the absence of upstream oceanic currents (Pullen et al. 2008). Using high-resolution air-sea modeling, monsoon surges during the winter season trigger oceanic eddy formation and propagation in the lee of the Philippines region of the South China Sea (SCS; Pullen et al. 2008). They are driven by the wind stress curl associated with the wind jets through the gaps of the island chain and wakes in the lee of the islands (Wang et al. 2008; Pullen et al. 2008). These wind jets and associated leeside wakes are caused by the airflow over the mountainous terrain of the Philippine archipelago. The strong winds blowing through gaps in mountain ranges or between islands occur in the presence of along-gap pressure gradients, which are a consequence of the partial blocking of cross-island monsoon flow by the mountains (Gaberšek and Durran 2004, 2006). Topographically constrained wind from high to low pressure was identified to be the dominant mechanism in valleys (Whiteman and Doran 1993) and mountainous terrain (Weber and Kaufmann 1998).

Additional eddy-formation regions have been identified within and around the Philippine archipelago using a high-resolution configuration of the Regional Ocean Modeling System (ROMS) and observations during the Philippine Straits Dynamics Experiment (PhilEx; Han et al. 2009). During the winter monsoon, aside from the cyclonic eddy in the lee of Mindoro (Wang et al. 2003; Pullen et al. 2008), cyclonic circulation was identified in the observed and simulated currents flowing northward, 

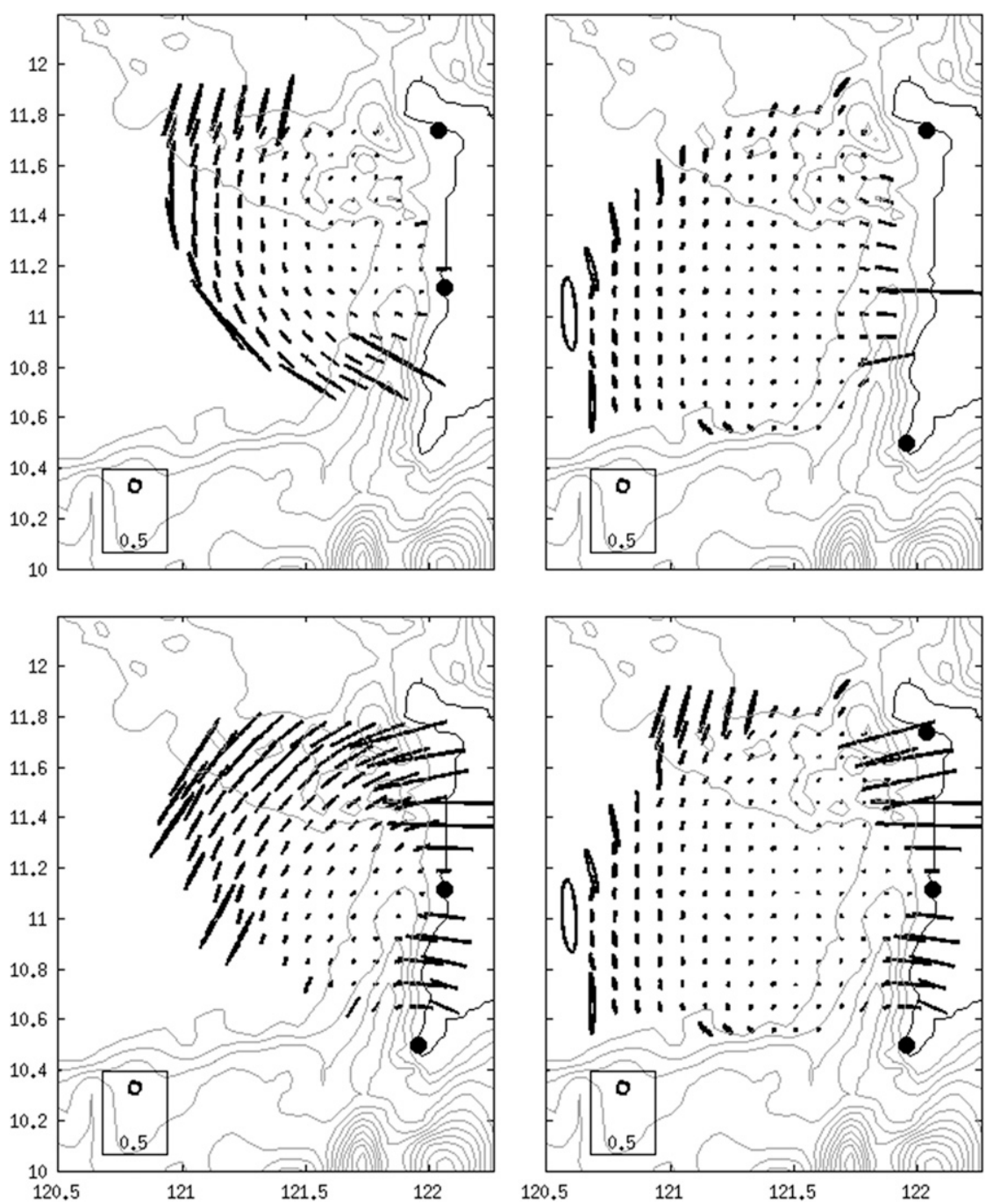

FIG. 2. GDOP ellipses for various geometric configurations: (top left) between Pandan and Laua-an, (top right) between Pandan and Tobias Fornier, (bottom left) between Laua-an and Tobias Fornier, and (bottom right) between Pandan, Laua-an, and Tobias Fornier. The legend corresponds to the threshold value to discard vector current data that are poorly constrained.

west of Panay Island (Han et al. 2009). In contrast, during summer, no strong eddy flow pattern within this region has been observed. The Mindoro Strait eddy was found to be in geostrophic balance associated with the positive wind stress curl, while the Panay Strait circulation could not be resolved by the model. These eddies were confirmed using the near-surface velocity from the shipboard ADCP during the PhilEx regional intensive observational period in January 2008 (RIOP-08) cruise (Gordon and Villanoy 2011) to be a response to complex wind stress curl (Rypina et al. 2010; May et al. 2011; Pullen et al. 2011). The eddy field seasonal variability, however, was not resolved by these one-time hydrographic cruises and model results with known errors and limitations. In addition, the missing data in the upper $40 \mathrm{~m}$ from the moored ADCP over Panay Sill made the connection of the nearsurface flow to monsoon variability more problematic (Sprintall et al. 2012).

This paper uses integrated in situ and remote sensing analysis collected over a year (August 2008-August 2009) to improve understanding of Panay Strait circulation and investigates its forcing mechanisms. The sampling campaign was part of the PhilEx.

The detailed deployment, instrumentation used, and methods to obtain low-frequency variability of the flow are presented in section 2 . The low-frequency observations and the forcing mechanisms of the cyclonic eddy are discussed in section 3 . The summary and conclusions are in section 4 . 


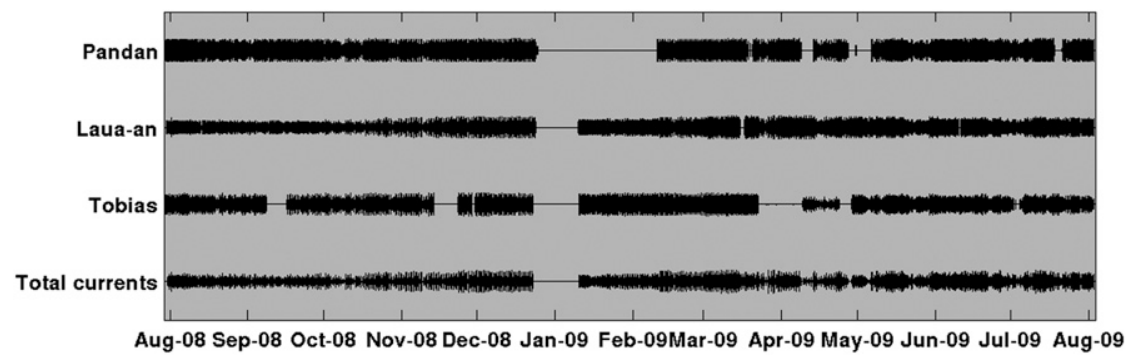

FIG. 3. Temporal coverage of the three HF radar sites and of the combined vector currents. The thickness corresponds to the percentage of grid points with data. The percentage of data obtained during the operation is $70.3 \%$ for Pandan, $72 \%$ for Laua-an, $70.6 \%$ for Tobias Fornier, and $79.4 \%$ for the vector currents.

\section{Environmental and instrumental setting}

\section{a. Physical setting}

The Panay Strait serves as the major pathway of South China Sea Water entering through the Mindoro Strait into the deep Sulu Sea basin (Fig. 1). The strait is bounded by the coast of Panay Island on the east and the Palawan Island chain on the west. Along Panay, the shelf is narrow (less than $10 \mathrm{~km}$ ), while the northern Palawan Shelf extends eastward as the shallow Cuyo Shelf. This then forms a deep channel close to the coast of Panay, based on $100-\mathrm{m}$ isobath with sill depth of about $570 \mathrm{~m}$. On the shelf lies the low-lying Cuyo group of islands and extensive reefs.

The flow within the strait is modulated by a range of processes such as tidal variations, seasonal reversal of the monsoon, sea level variations between SCS and the Pacific Ocean, interannual variations such as El NiñoSouthern Oscillation (ENSO), and episodic occurrence of monsoon surges and tropical cyclones (White et al. 2003; McClean et al. 2005; Pullen et al. 2008; Han et al. 2009; May et al. 2011).

\section{b. Instrumental setting}

Three short-wave ocean-current-mapping radars were deployed along the west coast of Panay Island to measure surface circulation from July 2008 to August 2009 during the PhilEx program (Fig. 1). This observational component aims to quantitatively describe the mesoscale spatial structure and the temporal variability of the surface currents within Panay Strait. The antenna at each site are grouped in a receive array and a transmit array. The northernmost and southernmost sites located in Pandan and Tobias Fornier, Philippines, respectively, include a linear array of 12 receiving antenna, whereas the middle site at Laua-an, Philippines, consists of a linear array of 8 receiving antenna. The four transmit antenna arranged in a rectangular array formed a beam toward the ocean, and a null in the direction of the receive antennas, to reduce the direct path energy. This also reduced the range away from the beam axis.

For each high-frequency Doppler radar (HFDR), radial currents are measured by transmitting a radio signal at $12 \mathrm{MHz}$ frequency. The radio waves are reflected by surface gravity waves having half the electromagnetic wavelength ( $\lambda=25 \mathrm{~m}$; Bragg scattering) of the transmitted signal and are then recorded by the receive antenna. The backscattered radio waves generate a Doppler-shifted signal in which the frequency shift is used to calculate the currents moving toward or away from the site. Vector currents were estimated on a $5-\mathrm{km}$ Cartesian grid by least squares fitting zonal and meridional components of the radial measurements from at least two sites within a $5-\mathrm{km}$ search radius. The range of HFDR data used for analysis was limited by geometric dilution of precision (GDOP; Chapman et al. 1997) that resulted from the normal velocity component being poorly constrained near the baseline between the sites, and the azimuthal component being poorly constrained far from the sites (Fig. 2). Vector current estimations with a GDOP greater than 0.5 were discarded (Chavanne et al. 2007).

Periodically, missing observations at long ranges (presumably due to diurnal variation of ionospheric propagation and absorption) were resolved by linear interpolation carried out on the vector currents (Chavanne et al. 2007, appendix B therein). The least squares analysis was carried out on the interpolated time series. Temporal coverage of the individual sites and of vector current estimations is shown in (Fig. 3). Vector currents with $75 \%$ temporal coverage were used for analysis.

Failures in HFDR occurred at sites because of electrical power loss primarily due to burned power cables and generator failures during blackouts. In times when data were lost from one site, two sites were used to calculate vector currents. During the deployment period, the largest data loss was during the bistatic calibration performed from 22 December 2008 to 9 January 2009. 

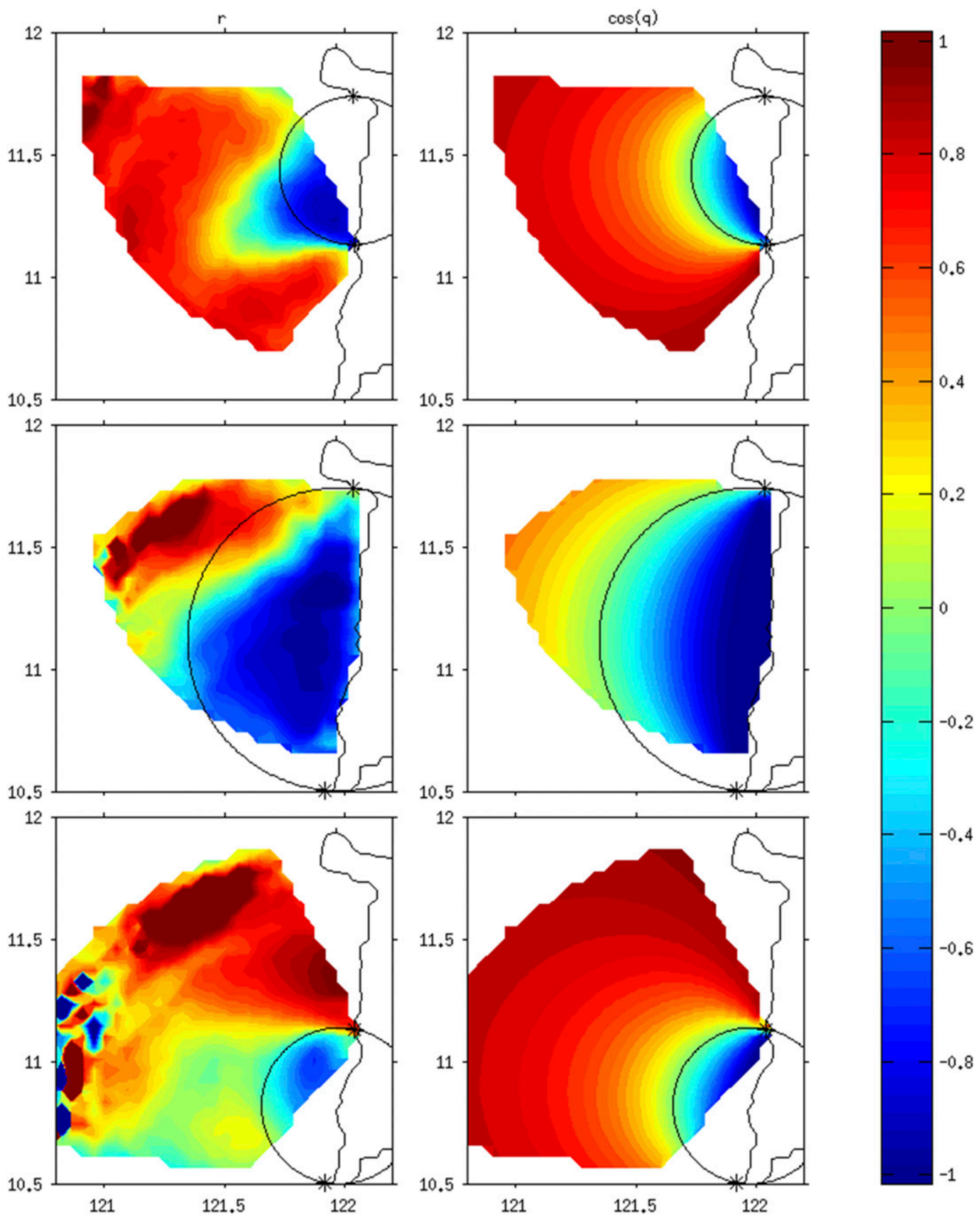

FIG. 4. (left) Cross correlation between radial currents from pairs of sites, and (right) cosine of the angle between the sites for (top) Pandan and Laua-an, (middle) Pandan and Tobias Fornier, and (bottom) Laua-an and Tobias Fornier. The circle where the angle between the two sites is $90^{\circ}$ is overlaid for reference.

Data quality was evaluated by cross correlations between radial currents from pairs of sites (Fig. 4). If along-baseline and across-baseline current components were uncorrelated with equal variance, the correlation pattern would follow that of the cosine of the angle between the two sites, indicating accuracy of measurements (Chavanne et al. 2007, appendix $\mathrm{C}$ therein). To further assess the accuracy of the HFDR, beamforming calibration onboard a motorized boat was also conducted for each of the three sites.

In conjunction with the HFDR, an ADCP mooring was deployed as part of the PhilEx exploratory cruise onboard the R/V Melville in June 2007 to provide aspects of the full three-dimensional circulation in Panay Strait. An upward-looking R. D. Instruments (RDI) Long 


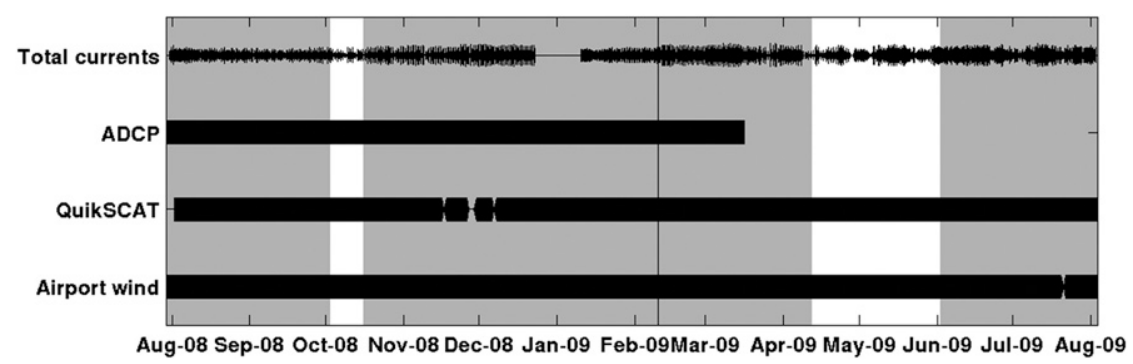

FIG. 5. Temporal coverage of the HFDR combined vector currents, ADCP current profile, QuikSCAT, and Caticlan Airport winds. The thickness corresponds to the percentage of grid points with data. The percentage of data is $79.4 \%$ for the vector currents, $100 \%$ for current profile, $98.7 \%$ for QuikSCAT, and $99.8 \%$ for the airport wind. The vertical line marked the RIOP-09 cruise. The NE (November-March) and SW (June-October) monsoon are shaded accordingly

Ranger $75 \mathrm{kHz}$, bottom-mounted ADCP was located inside the region covered by HFDR, $2.5 \mathrm{~km}$ downstream from the narrowest constriction of Panay Sill at 578-m water depth. The ADCP included pressure and temperature sensors. Sampling rates, set to resolve the tides, were $30 \mathrm{~min}$ for the ADCP and $15 \mathrm{~min}$ for the temperature and salinity sensors. The mooring was recovered in March 2009. The ADCP returned $100 \%$ of the velocity time series. However, because of surface-reflection contamination, the bottom-mounted ADCP was unable to resolve the near-surface velocity (upper $40 \mathrm{~m}$ ). Pressure time series were corrected from mooring blow over. The velocity data were then linearly interpolated in the vertical onto a 10-m depth grid and a common time base of $1 \mathrm{~h}$.

The gridded daily wind vector and wind stress fields, estimated over the global ocean from QuikSCAT scatterometer were obtained online at L'Institut Français de Recherche pour l'Exploitation de la Mer (IFREMER; ftp:// ftp.ifremer.fr.fr/ifremer/cersat/products/gridded/MWF/ L3/QuikSCATDaily). The daily wind fields were calculated for the full QuikSCAT, version 3 (V3), period: October 1999-November 2009 with spatial resolution of $0.25^{\circ}$ in longitude and latitude. The reference height of wind data is $10 \mathrm{~m}$. This new scatterometer product is

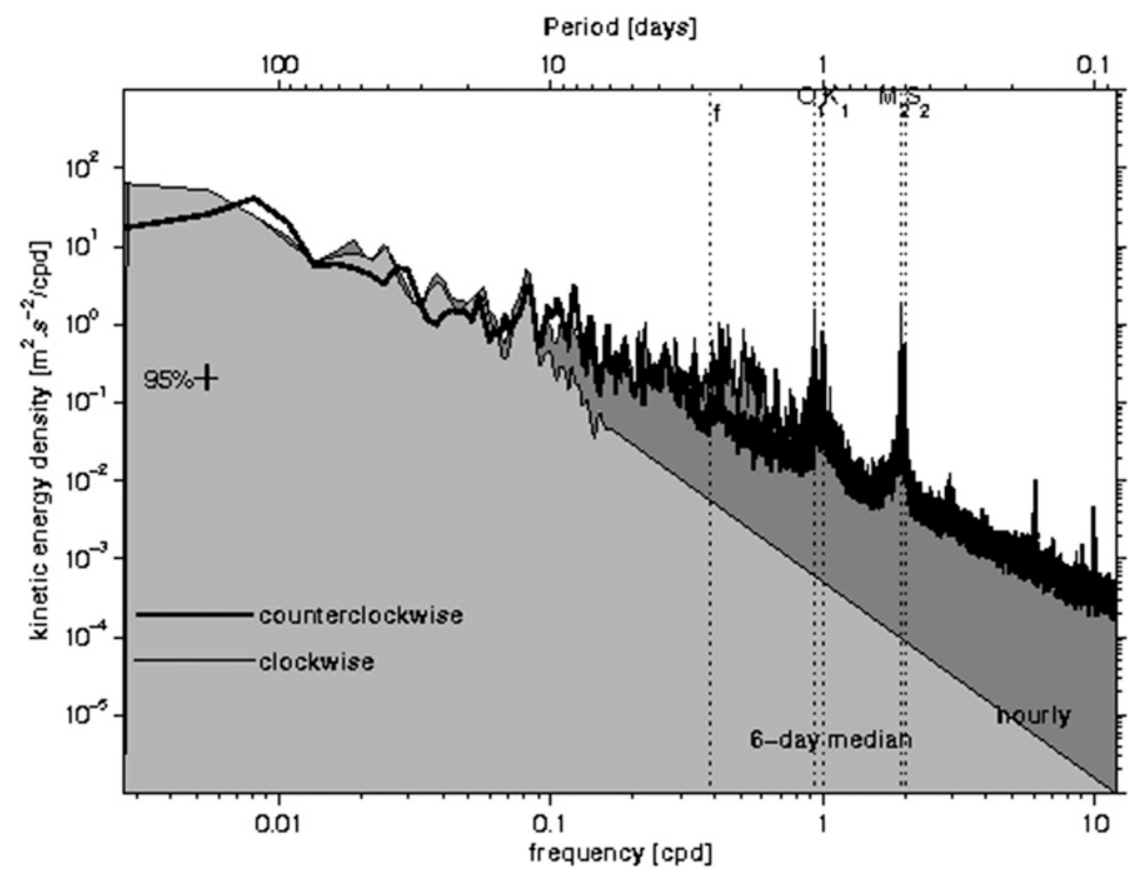

FIG. 6. Rotary power spectra of hourly (dark gray) and 6-day median (light gray) HFDR data averaged over an area with more than $75 \%$ temporal coverage. Major tidal constituents $\left(\mathrm{O}_{1}, \mathrm{~K}_{1}, \mathrm{M}_{2}\right.$, and $\left.\mathrm{S}_{1}\right)$ and inertial frequency $f$ are indicated on the top $x$ axis. 

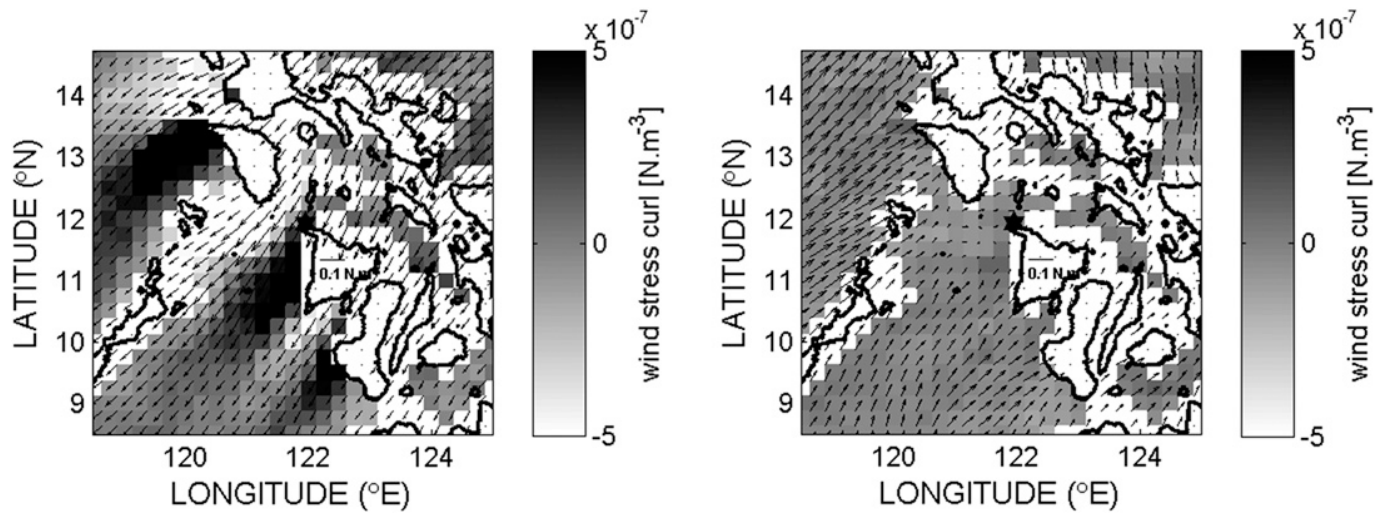

FIG. 7. Wind stress and curl from QuikSCAT at 25-km resolution, averaged over HFDR period during the (left) NE monsoon (November-March) and (right) SW monsoon (May-September). Marked with a black star in the left panel is the Caticlan Airport, where observed wind data was obtained and correlated with the nearest QuikSCAT wind data shown in Fig. 8.

assumed to have improved wind speed performance in rain and at high-wind conditions. In addition, in situ $10 \mathrm{~m}$ daily wind data from the nearby Caticlan Airport was obtained (Fig. 1).

A regional intensive observational period in February 2009 (RIOP-09) was conducted covering the MindoroPanay Strait complex, a particular focus of PhilEx. Directed by near-real-time surface current from HFDR central processing station, an intensive hydrographic survey of the cyclonic eddy observed over Panay Strait was carried out. A 24-h (0607:21 UTC 8 February-0701: 44 UTC 9 February 2009) successive cross-shore sections using the MacArtney TRIAXUS-towed undulating vehicle equipped with Sea-Bird temperature and conductivity sensors along with hull-mounted shipboard Ocean Surveyor $150 \mathrm{kHz}$ ADCP were obtained. A total of six transects were occupied, each spans $77 \mathrm{~km}$ across the strait. Daily atmospheric COAMPS


FIG. 8. Time series of wind vectors from nearby Caticlan Airport and QuikSCAT from the closest grid point. Correlations $R$ (the numbers in parentheses indicate the $5 \%$ statistical significant level) and RMS diff are indicated in the top plot for zonal $U$ and meridional $V$ components. 

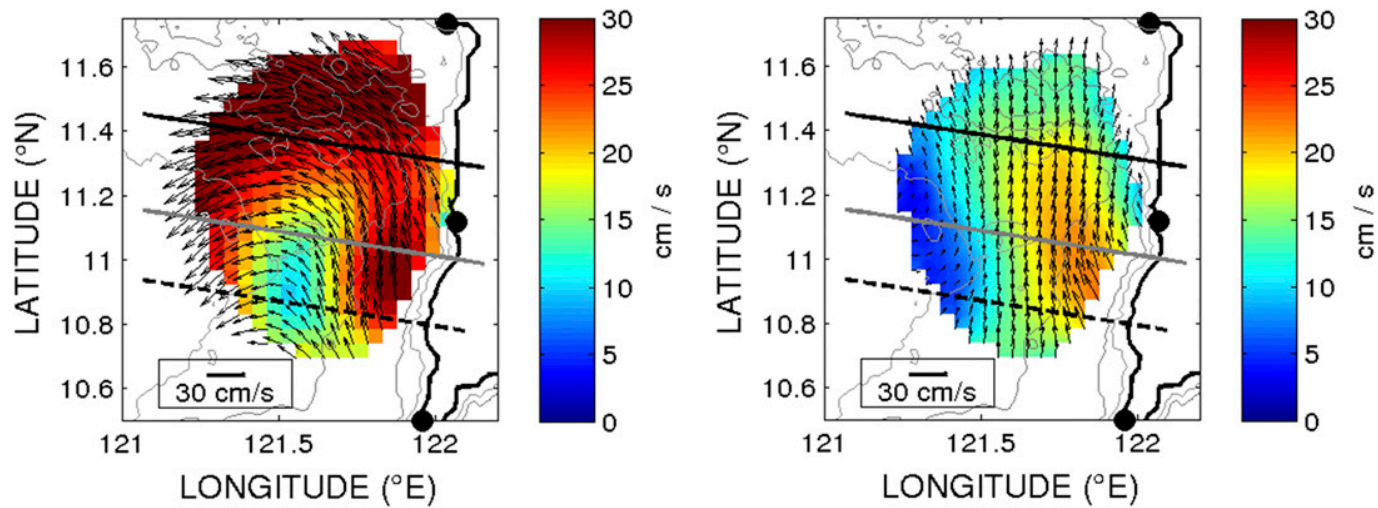

FIG. 9. Mean surface ocean-current vectors overlaid by its speed, color contoured $\left(\mathrm{cm} \mathrm{s}^{-1}\right)$ during the (left) NE monsoon and (right) SW monsoon period. Three transects are marked accordingly, along which mean surface flow profiles are shown in Fig. 10.

forecasts, described by May et al. (2011), and satellite images of wind speed provided as real-time support to the shipboard team were also used for analyses.

\section{c. Instruments and data processing}

An intensive observation of Panay Strait was carried out to describe the mesoscale spatial structure and temporal variability of the surface current within the strait. Figure 5 shows the temporal coverage of the data that span over a year, covering the Asian monsoon reversal.
The northeast (NE) monsoon is between November and March, whereas the southwest (SW) monsoon is between June and October (Wang et al. 2001).

Tidal components of surface currents from HFDR and the current profile from moored ADCP were separated out by performing a harmonic tidal analysis using T-TIDE, an open-source MATLAB toolbox as described by Pawlowicz et al. (2002). It was then subtracted from the original data to obtain the residuals. The residuals were further subjected to a 6-day running median to
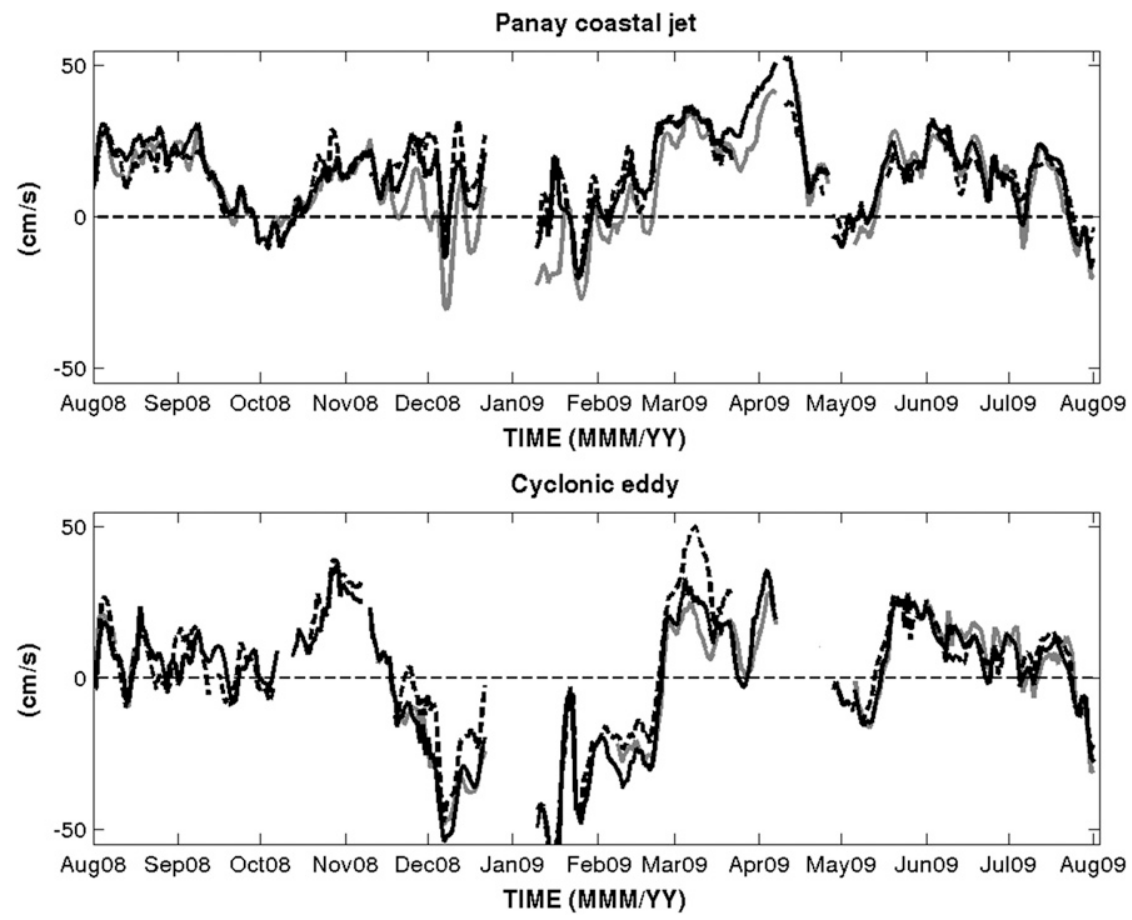

FIG. 10. Time series of profiles of the (top) PC jet and (bottom) cyclonic eddy return flow. Positive (negative) values indicate flow toward the north (south). The negative (southward) flow indicates the presence of the cyclonic eddy. The line color and type corresponds to three transects in Fig. 9. 

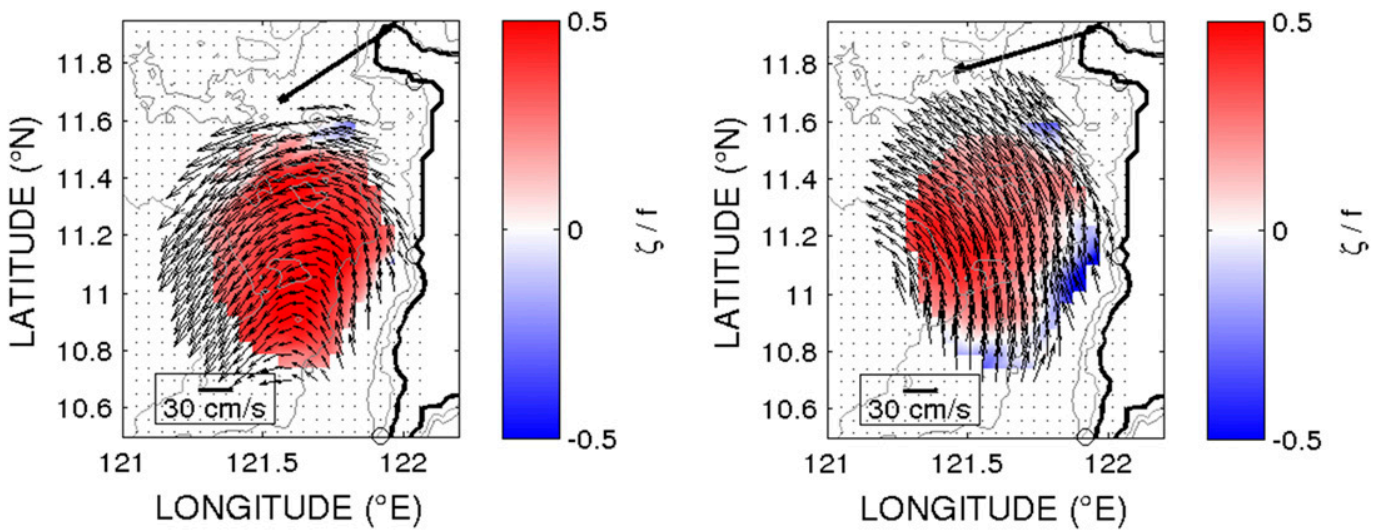

FIG. 11. Mean surface flow overlaying vorticity $\zeta$, normalized by $f$ contours during the (left) peak (15 Jan-23 Feb 2009 ) and (right) waning (25 Feb-1 Apr 2009) NE monsoon. The arrows indicate the mean prevailing wind vectors from the Caticlan Airport.

reduce spectral leakage and to get the time series in which tides and near-inertial oscillations (2.6 days) have been cautiously filtered out to isolate mesoscale processes. The Cartesian velocities were rotated into alongshore velocities based on the orientation of the coast of Panay Island $\left(9^{\circ} \mathrm{N}\right)$. The similar 6 -day running median was also applied to the daily wind data from Caticlan Airport and QuikSCAT satellite. Figure 6 shows the spatially averaged rotary spectra of the hourly and 6-day median surface current from HFDR where high-frequency variability was removed.

\section{Results}

\section{a. Local wind variability}

The monsoon is traditionally defined as a seasonally reversing wind system. The alternation of dry and wet seasons is in concert with the seasonal reversal of the monsoon circulation. The reversal is due to the differential heating of land and the oceans, the Coriolis force, and moist processes that determine the strength and location of the major monsoon precipitation (Webster et al. 1998).

Panay Strait in the Philippines is situated within the strong influence of the Asian monsoon winds that blow from the NE between November and March and from the SW between June and October. The wind field exhibits pronounced seasonal variations between the NE and SW monsoon periods (Fig. 7). Northeasterly winds are stronger and more stable than southwesterly winds, producing wind jets in between islands, generating a distinctive spatial pattern of alternating bands of positive curl on the left flank and negative curl on the right of Luzon, Mindoro, Panay, and Negros Islands, Philippines. Consequently, positive curl on the north flank of Panay is enhanced, dominating the lee and presenting a favorable condition for the formation of mesoscale eddies during the NE monsoon. These features are not evident during the SW monsoon period, which is characterized by weaker, highly variable winds.
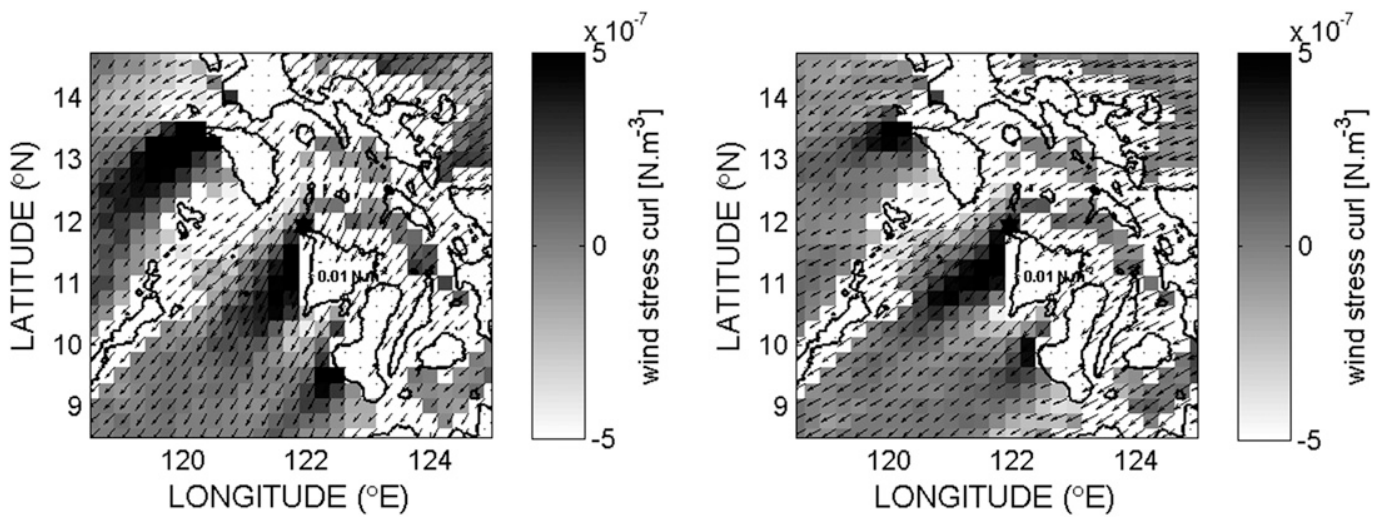

FIG. 12. Wind stress vectors overlaying the wind stress curl contours during the (left) peak (15 Jan-23 Feb 2009) and (right) waning (25 Feb-1 Apr 2009) NE monsoon from QuikSCAT. 


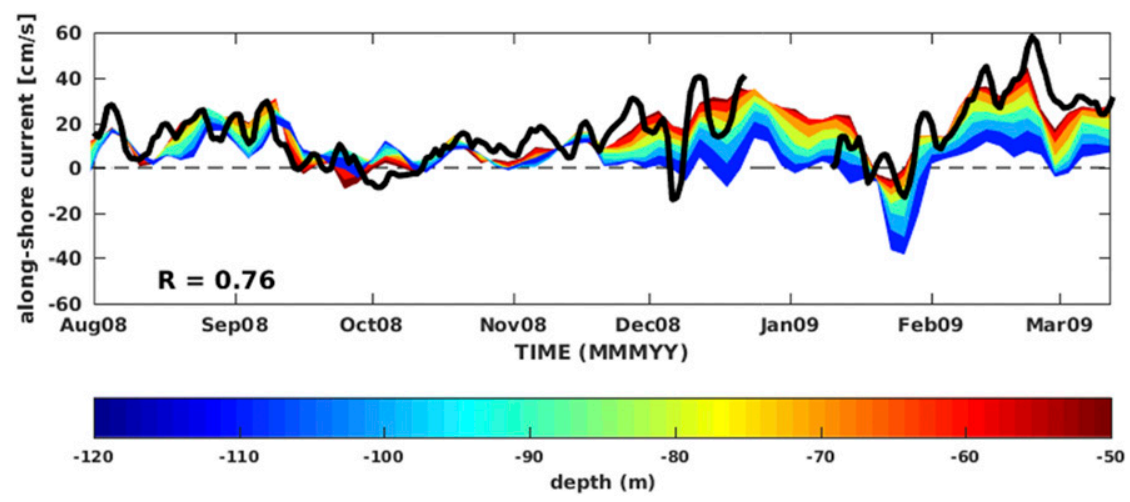

FIG. 13. Time series of alongshore current from moored ADCP (contoured) overlaid with alongshore surface current from the closest HFDR data (thick black line). Correlation $R$ between HFDR and 50-m-depth bin ADCP alongshore currents is indicated.

Wind vectors from the nearby airport are reasonably comparable with the QuikSCAT wind from the closest grid point (Fig. 8). Correlation $R$ of zonal $U$ and meridional $V$ wind components between the two datasets are 0.93 and 0.94 with root-mean-square differences (RMS diff) of 1.69 and $4.09 \mathrm{~m} \mathrm{~s}^{-1}$, respectively. An abrupt reversal of the wind regime is evident, marked by a welldefined transition periods (October and April) followed by the short phases of weakening (Fig. 8). Persistent northeasterly winds occur from October to mid-April, and southwesterly winds prevail from May to September, with pronounced subseasonal breaks. These break periods are an important characteristic of the SW monsoon in Southeast Asia, and they have been associated with westward-propagating atmospheric equatorial waves (Chen and Weng 1996). The strongest winds during the NE monsoon are in January. October and April-May mark the transition periods between the NE monsoon and the SW monsoon, respectively.

\section{b. Surface ocean-current patterns}

Surface wind forcing is particularly evident in the circulation patterns in and around the Philippine archipelago. In Panay Strait, which is subject to pronounced Asian monsoon reversal, observed surface flow patterns are highly seasonal with well-defined transition periods. Mean flow during the NE monsoon (November 2008March 2009) is characterized by a jetlike northward flow, referred to here as the Panay coastal (PC) jet, and a southwestward return flow forming a cyclonic circulation (Fig. 9, left). In contrast, the SW monsoon period is characterized by a relatively weak northward PC jet, with significant weakening and modification over the shallow Cuyo Shelf (Fig. 9, right; combined for AugustSeptember 2008 and June-July 2009).

Time series of the PC jet and cyclonic eddy return flow over the three cross-shore transects in Fig. 9 are shown in Fig. 10. The PC jet is defined as the mean surface current from the coast to the center of the eddy where the mean
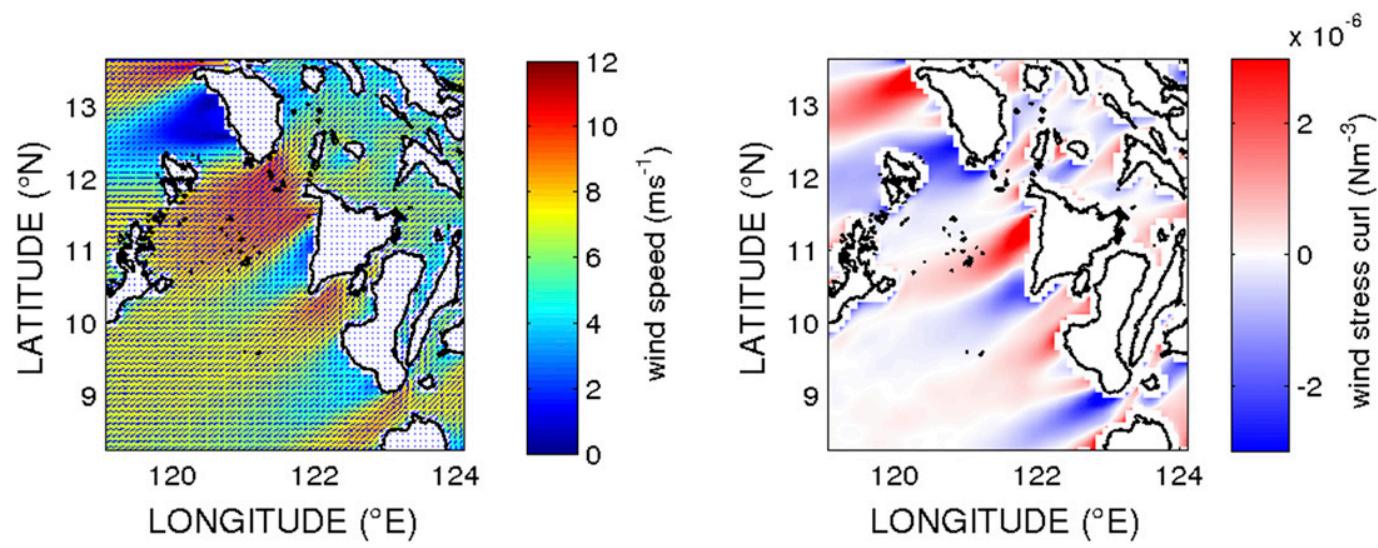

FIG. 14. The COAMPS (left) $10-\mathrm{m}$ mean wind, wind vectors plotted over wind speed contour ( $\left.\mathrm{m} \mathrm{s}^{-1}\right)$, and (right) mean wind stress curl contour $\left(\mathrm{N} \mathrm{m}^{-3}\right)$ from the 9-km computational grids for RIOP-09. 


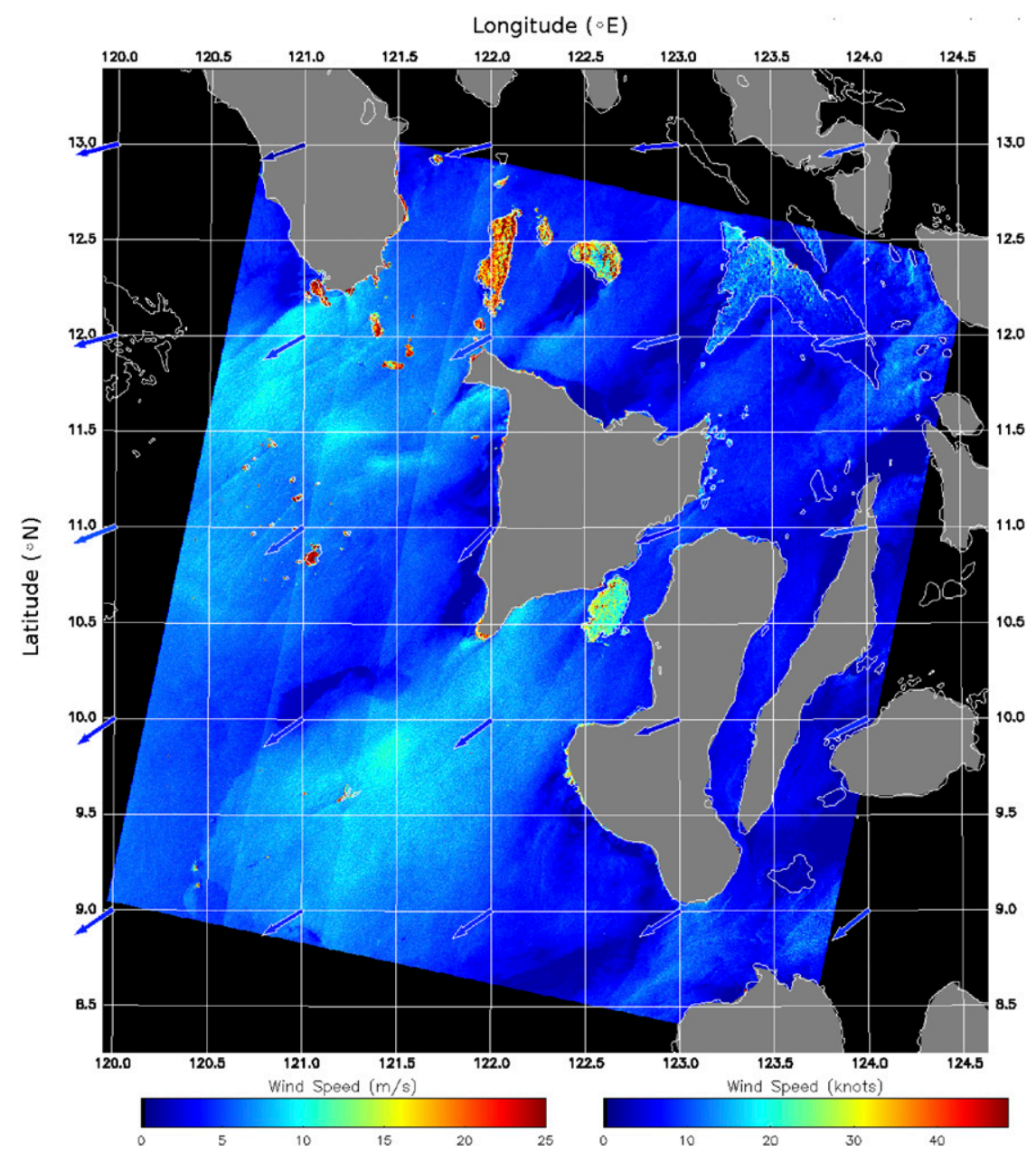

FIG. 15. Surface wind speeds derived from an Envisat ASAR image using the Johns Hopkins University Applied Physics Laboratory (APL)/NOAA SAR Wind Retrieval System (ANSWRS) for 0141 UTC 7 Mar 2009. The colorbar on the left is in meters per second, while on the right in knots $\left(\mathrm{kt} ; 1 \mathrm{kt} \approx 0.51 \mathrm{~m} \mathrm{~s}^{-1}\right)$. Image courtesy of NOAA/NESDIS/Office of Research and Applications/STAR and Christopher Jackson, Global Ocean Associates. Wind vectors are from the Navy Operational Global Analysis and Prediction System (NOGAPS) model.

flow is zero, while the cyclonic eddy return flow is defined as the mean surface current from the center of the eddy to the west over which HFDR data are available. Mean flow time series clearly exhibit the most dominant features, the steady PC jet and the seasonal cyclonic eddy. The three transects show comparable strength of the dominant flows over Panay Strait and depict the size of the eddy occupying the whole HFDR domain.

The PC jet is generally northward as indicated by positive mean surface current (Fig. 10, top). It persists from mid-May to September with noticeable weakening during early May and October, which coincides with the relaxation of the monsoon winds during transition periods. In contrast, the cyclonic eddy is highly seasonal (Fig. 10, bottom). It forms during the NE monsoon as indicated by southward (negative) mean surface current in mid-November and intensifies during the peak of the NE monsoon (December-February), dominating over the HFDR domain. As the eddy strengthens in January along with the progressing NE monsoon, it moves close to the coast, resulting in a more southward mean flow and weaker PC jet. By March, a considerable westward shift of the cyclonic eddy leads to an intensified PC jet, which replaces the eastern limb of the eddy.

\section{Discussion}

\section{a. Evidence for a wind-induced cyclonic eddy-formation mechanism}

From the analysis of the wind (Fig. 8) and surface current (Fig. 10), the first signature of the cyclonic eddy west of Panay appears in mid-November, about a month 

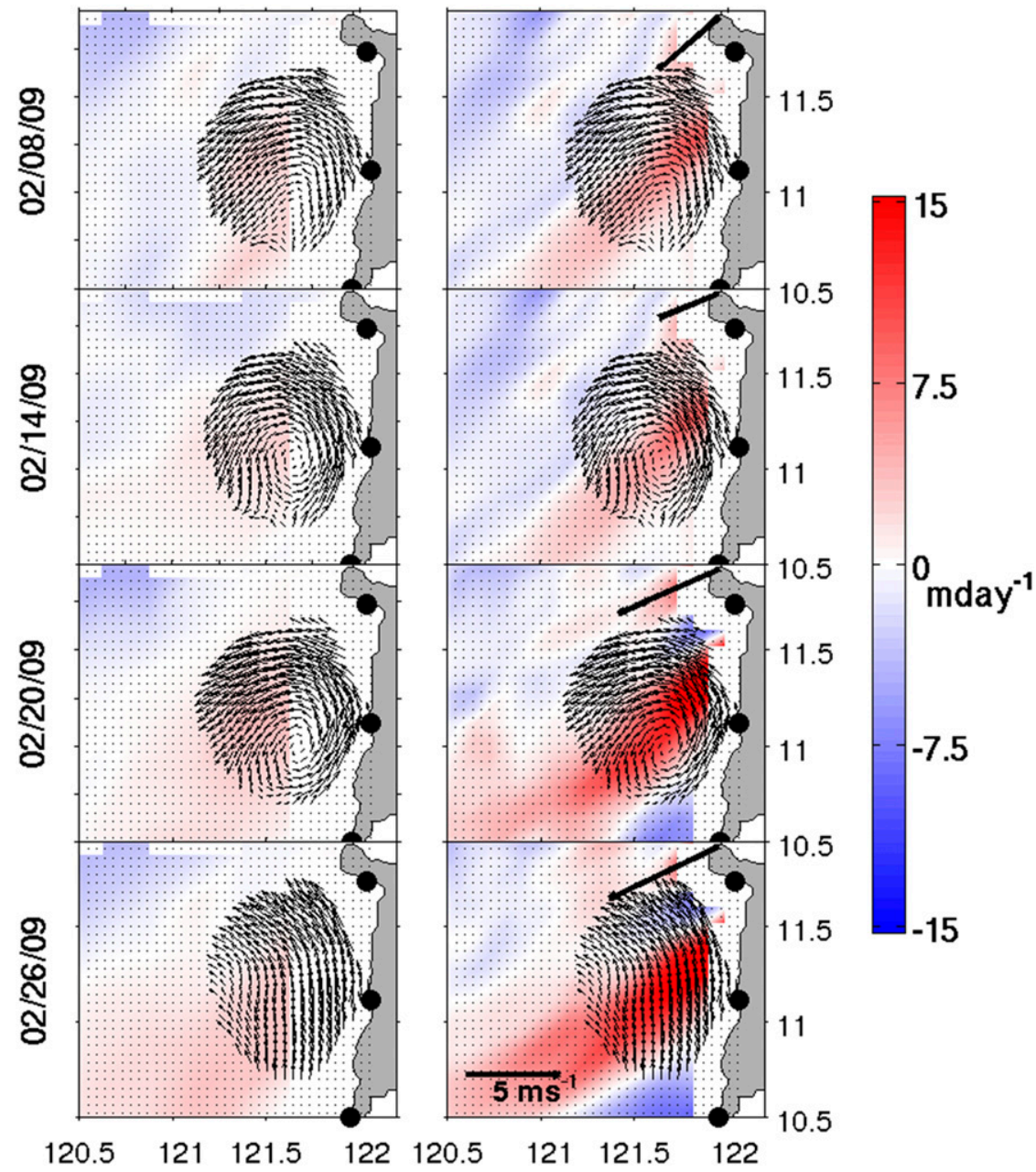

FIG. 16. Snapshots of surface current overlaid with contoured Ekman pumping velocity calculated from (left) QuikSCAT and (right) COAMPS wind. Wind vectors at Caticlan Airport (thick arrows) are also indicated.

and a half after the NE monsoon prevails over the area. It strengthens with progressing northeasterly wind, then gradually shifts westward and is replaced by the enhanced northward PC jet. Figure 11 shows a shift in the location of the eddy as the wind veered to a more easterly orientation during the waning NE monsoon (from mid-February to mid-April) from the observed airport wind and in the snapshots of QuikSCAT wind stress and wind stress curl (Fig. 12). As the eddy shifts westward, it widens and reinforces the PC jet, which is now the dominant flow pattern over the HFDR domain (Fig. 11).

During the NE monsoon, variations of the PC jet are mainly influenced by the eddy, evident in the current profile obtained from the moored ADCP (Fig. 13). Contoured alongshore current profile overlaid with alongshore surface current from the closest HFDR data (thick black line) shows a generally northward PC jet with pronounced intensification during the NE monsoon when the cyclonic eddy is generated. A southward flow at the end of January was also captured by the ADCP when the cyclonic eddy moves close to the coast as northeasterly winds intensify with a more northerly component. This northerly shift and intensification of monsoon winds were captured in a one-way coupled atmosphere and ocean simulation of the Philippine region described as monsoon surges (Pullen et al. 2008), which occur frequently during the winter season (Pullen et al. 2008; Chang et al. 2006; Wu and Chan 1995). These fluctuations in the monsoon winds induce a dynamic response. Specifically, the local injection of vorticity beneath episodically strengthened wind jets in which propagation direction is related to the orientation of the winds (Pullen et al. 2008).

The seasonal evolution of the cyclonic eddy appears to be an oceanic response to the prevailing local wind. 

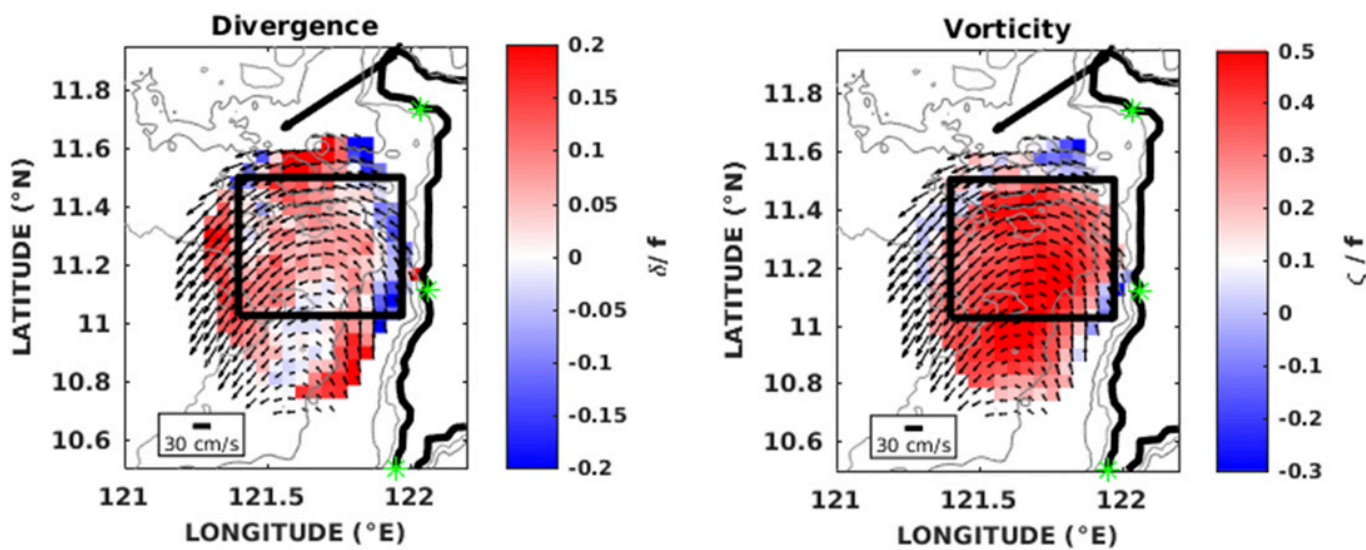

FIG. 17. Mean surface ocean-current overlaid with its contoured (left) divergence and (right) vorticity for February-March 2009 (RIOP-09).

Figure 14 shows the mean $10-\mathrm{m}$ wind and wind stress curl from COAMPS forecasts supplied to researchers on the PhilEx RIOP-09 cruises in real time, averaged over a 40-day period from mid-February through end of March 2009. The acceleration of the winds on the edges of the islands of Mindoro, Panay, and Negros and the weakening in its lee are well resolved. The surface wind derived from European Space Agency Envisat Advanced Synthetic Aperture Radar (ASAR) image [see Thompson and Beal (2000) on how to extract wind speed estimates from SAR] verifies the presence of wind jets and wakes (Fig. 15). Although the image is a snapshot (0141 UTC 7 March 2009), it was taken during the NE monsoon wind regime and agrees well with the general patterns that are apparent in the mean model winds shown in Fig. 14. As in the model, the strongest winds, nearly $10 \mathrm{~m} \mathrm{~s}^{-1}$, are in between Mindoro and Panay through the Tablas Strait. Figure 14 (right) shows the resulting wind stress curl dipoles reaching the magnitude of $10^{-6} \mathrm{~N} \mathrm{~m}^{-3}$ associated with each island. However, because of the orientation of Panay Island with respect to the NE monsoon wind, positive wind stress curl dominates in the lee, drastically affecting the ocean circulation.

Curl of the wind stress causes Ekman flux divergence and convergence, which in turn drives Ekman pumping. To conserve mass, a vertical velocity $w$ results, which is (Gill 1982)

$$
w_{E}=w\left(-H_{E}\right)=\operatorname{curl}_{z} \frac{\tau}{\rho f},
$$

where $w_{E}$ is the Ekman pumping velocity, $\tau$ is the surface wind stress, $\rho$ is the density of seawater $\left(1025 \mathrm{~kg} \mathrm{~m}^{-3}\right)$, and $f$ is the Coriolis parameter. A vertical velocity $w$ at the base of the Ekman depth $-H_{E}$ estimates the upwelling or downwelling proportional to the wind stress curl.
Figure 16 shows that the largest curl-driven Ekman pumping velocity over the Cuyo Shelf is in the lee of Panay Island, indicating an upwelling zone. Although the calculation using satellite wind is weaker than the modeled wind, both exhibit the same general pattern. The value of Ekman pumping velocity reaches up to $15 \mathrm{~m} \mathrm{day}^{-1}$ based on the snapshots of wind stress curl calculated from COAMPS wind. The instantaneous Ekman pumping velocities indicate a wind-induced divergent Ekman transport, which agrees with the mean

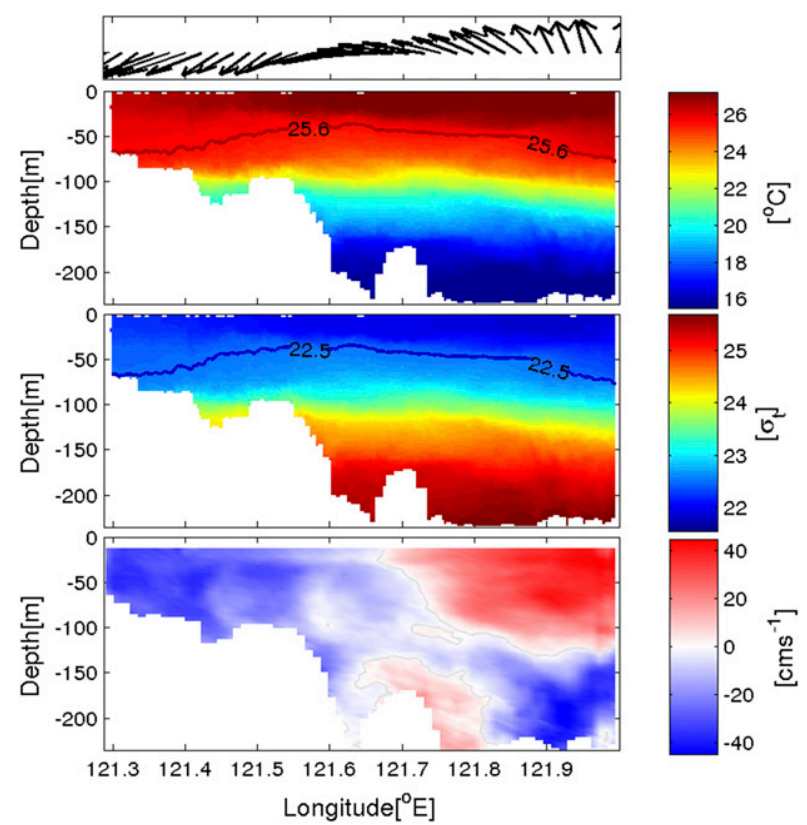

FIG. 18. Vertical transect of mean (top) temperature, (middle) density, and (bottom) alongshore flow from the shipboard ADCP across the Panay Strait during the hydrographic survey (8-9 Feb 2009) shown in Fig. 1. The mean near-surface alongshore flow vectors are indicated above. 


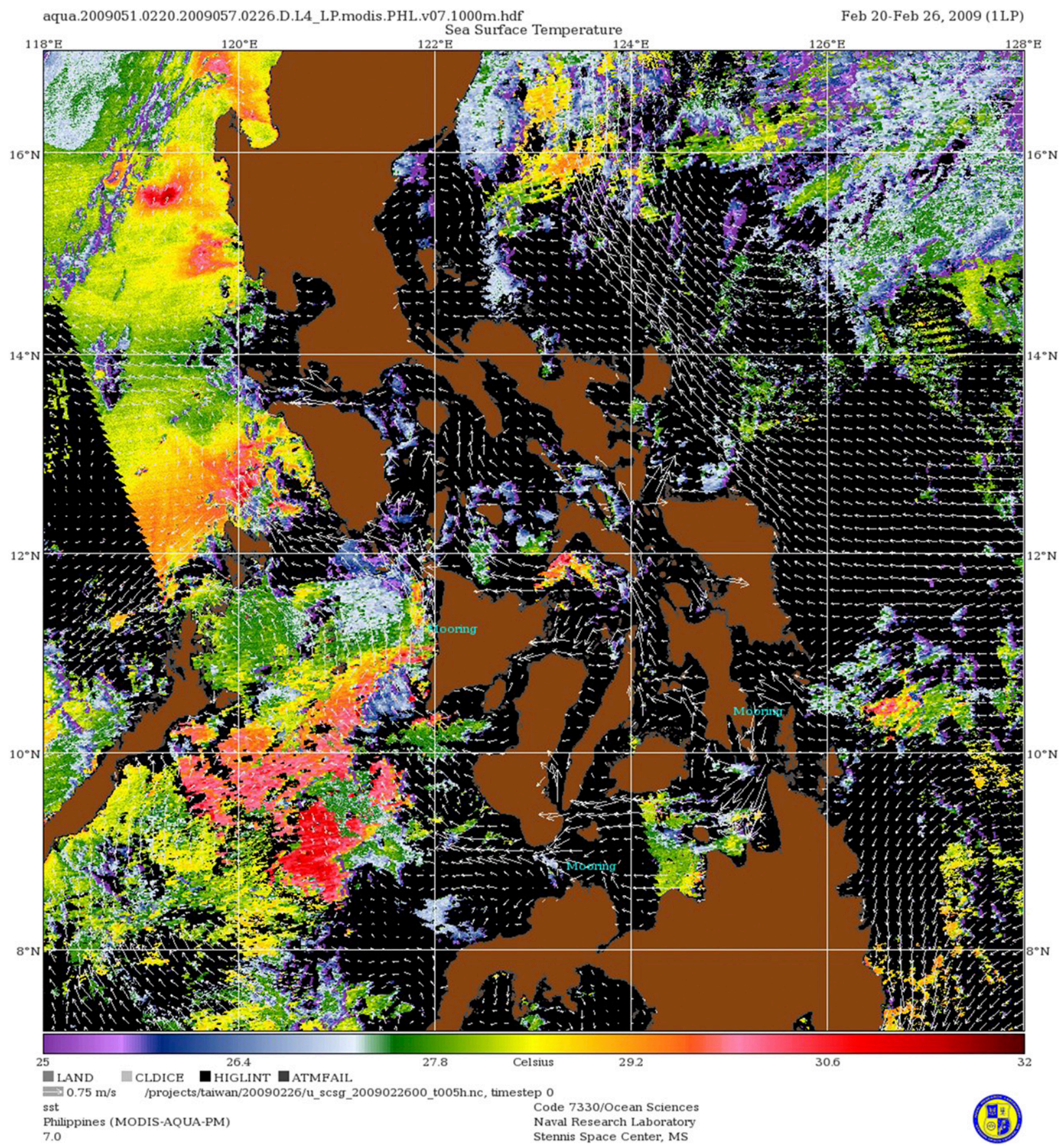

FIG. 19. The 1-km MODIS Aqua imagery SST 6-day composite image and model-derived [Hybrid Coordinate Ocean Model (HYCOM); Arango et al. 2011] surface current vectors of the Philippine archipelago for 20-26 Feb 2009. Image courtesy of Robert Arnone and Sherwin Ladner of Naval Research Laboratory, Stennis Space Center, Mississippi.

divergence calculated from HFDR in the lee of the island during the same time period (Fig. 17, left). As a result of surface divergence, the thermocline is lifted and the water column beneath is stretched, forming the Panay Dome. Figure 18 shows the mean profile of temperature (top) and density (middle) from the hydrographic cross-shore sections. The notable spreading of isotherms and isopycnals indicate a vertically mixed water column, which destroys the water column stratification. This brings cooler, denser, and nutrient-rich waters into the euphotic zone, leading to enhanced biological productivity over the region. Satellite images provided in real time to 


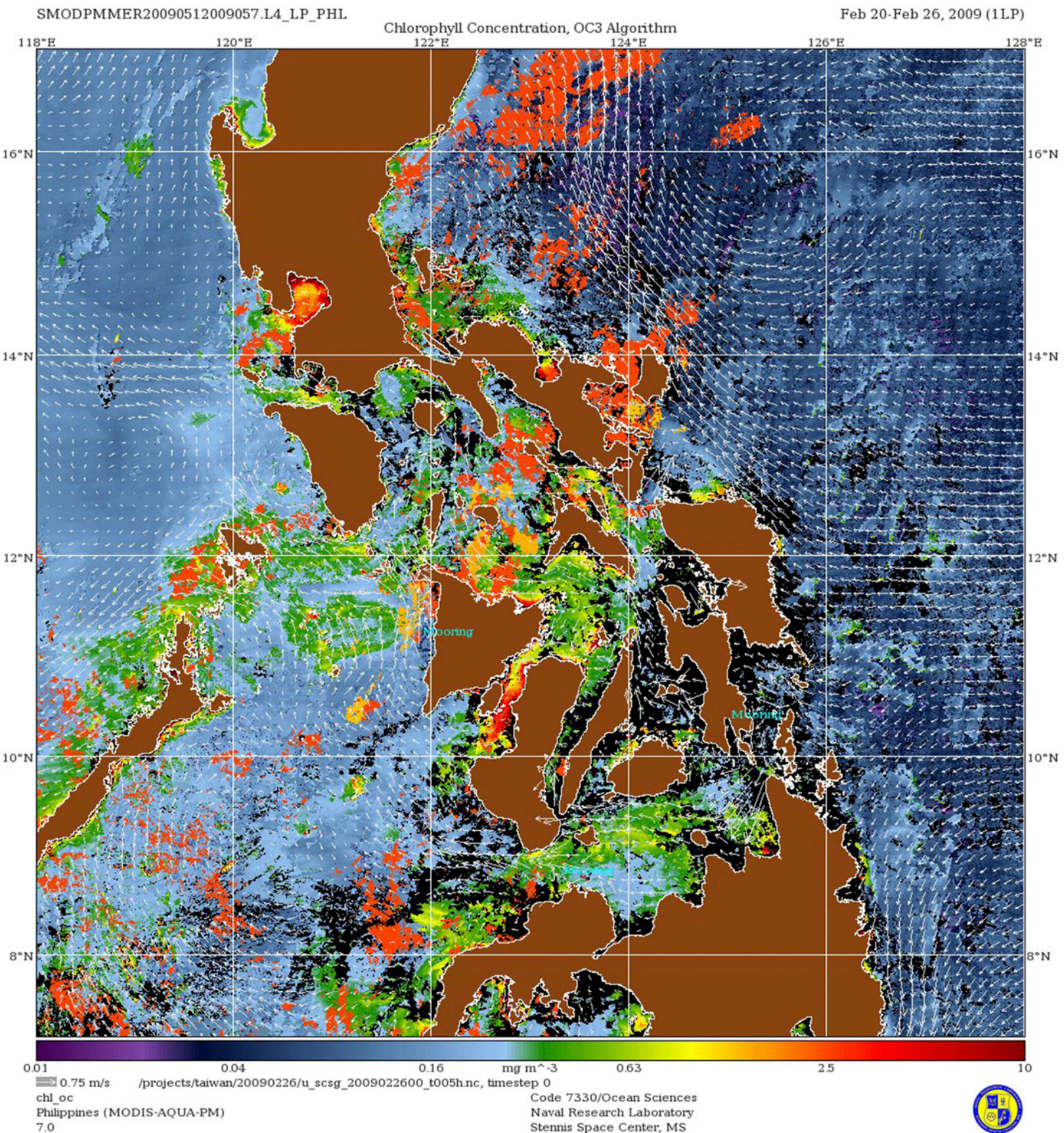

FIG. 20. The merged [MODIS, Medium-Resolution Imaging Spectrometer (MERIS), and SeaWiFS] chlorophyll 6-day composite image and model-derived (HYCOM; Arango et al. 2011) surface current vectors of the Philippine archipelago for 20-26 Feb 2009. Image courtesy of Robert Arnone and Sherwin Ladner of Naval Research Laboratory, Stennis Space Center.

support the RIOP-09 cruises confirmed cooler SST (Fig. 19) and enhanced chlorophyll concentration (Fig. 20) over the Cuyo Shelf, indicative of an active upwelling zone with pronounced annual cycle with peak occurring during the NE monsoon (Wang et al. 2006).

The doming of isotherms and isopycnals corresponds well with the return flow in the near-surface alongshore current from the shipboard ADCP, indicating the center of the eddy. The excursion of the isolines reaches around $50 \mathrm{~m}$. In the current profile (Fig. 18, bottom), the alongshore return flow reaches a depth of about $130 \mathrm{~m}$, indicating the depth of the eddy. Velocities at the surface reached mean values of $50 \mathrm{~cm} \mathrm{~s}^{-1}$. The flow structure is nearly depth independent over 

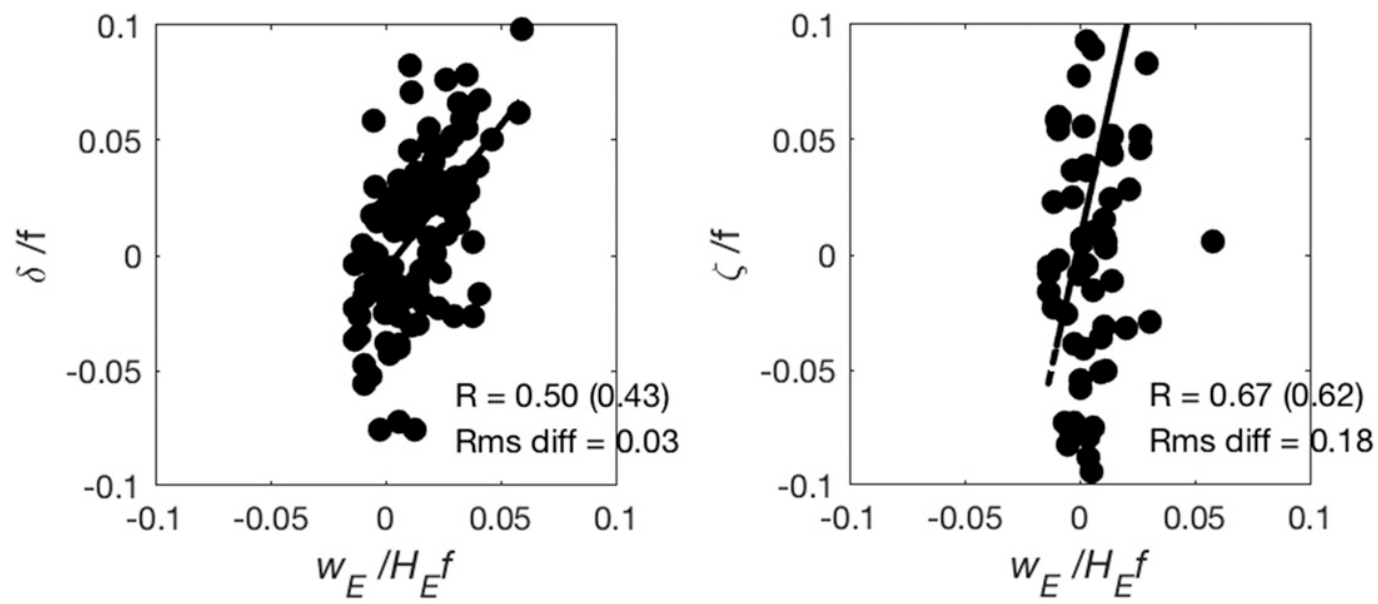

FIG. 21. Scatterplots of mean (left) divergence vs Ekman pumping velocity and (right) vorticity vs Ekman pumping velocity. Divergence and vorticity were calculated using HFDR data, while Ekman pumping velocity was calculated using COAMPS from the region inside the box shown in Fig. 17 during February-March 2009 (RIOP09). Correlations $R$ (the numbers in parentheses indicate the $95 \%$ confidence null hypothesis values) and RMS diff are indicated in the bottom-right corner of each panel.

the shallow shelf, whereas a strong southward flow below $150 \mathrm{~m}$ is evident at the deep channel in the strait. Sprintall et al. (2012) observed similar southward flows as extraordinarily strong pulses that begin at intermediate depth in the fall transition and shoal toward the subthermocline during the NE monsoon found both in Mindoro and Panay Straits ADCP moorings. These southward flows are strongly correlated with the changes in the South China Sea large-scale circulation and remote wind forcing off Vietnam (Sprintall et al. 2012).

The uplift in the thermocline sets up a horizontal pressure gradient, which consequently spins up the geostrophic cyclonic eddy. The eddy formation is evident in the mean vorticity overlaid by the surface current from HFDR (Fig. 17, right), in which the center coincides with the location of largest Ekman pumping and the doming.

If the divergence is entirely wind driven and confined within the Ekman depth, divergence should be proportional to the Ekman pumping velocity at the base of the Ekman layer. That is,

$$
\delta=\nabla_{h} \cdot \bar{u}_{h}=\frac{w_{E}}{H_{E}},
$$

where $\delta=\nabla_{h} \cdot \bar{u}_{h}$ is the divergence, subscripts $h$ denote horizontal components, and $w_{E}$ is the Ekman pumping velocity at constant Ekman depth $H_{E}=32 \mathrm{~m}$ determined as the best fit between the integrals of Ekman pumping velocity and divergence, respectively.

Figure 21 shows the correlation between divergence (left) and Ekman pumping velocity and between vorticity and Ekman pumping velocity (right) averaged over a specified region (Fig. 17, box). All of the terms have been normalized by $f$ in order to facilitate comparison. The divergence and vorticity are closely linked together to Ekman pumping velocity, with correlation coefficients of $R=0.50$ and $R=0.67$ and RMS diff values of 0.03 and 0.18 , respectively.

\section{b. Dynamical analysis of the cyclonic eddy}

Vorticity input to the ocean from the overlying wind stress curl appears responsible for the cyclonic eddy generation and evolution during the NE monsoon. By estimating the surface vorticity balance of the lowfrequency surface current, wind contribution to the generation and evolution of the vortex was assessed by

$$
\frac{D \zeta}{D t}=-(f+\zeta) \delta-v \beta+R,
$$

where $D \zeta / D t=\partial \zeta / \partial t+u \cdot \nabla \zeta$ is the rate of change of vorticity following the fluid motion, $(f+\zeta) \delta$ is the vortex stretching, $v \beta$ is the beta-effect term, where $v$ is the meridional velocity and $\beta$ is the meridional spatial derivative of $f$, and $R$ is the residual term, assumed to be due to friction and unresolved dynamics. Vorticity changes associated with sloping topography were neglected.

Assuming that the momentum flux from the surface is due to wind stress, its contribution to $R$ is

$$
R_{w}=\frac{1}{\rho H_{E}} \operatorname{curl}_{z} \tau,
$$

where $\rho=1025 \mathrm{~kg} \mathrm{~m}^{-3}$ is the density of seawater, $H_{E}$ is the Ekman depth, and $\operatorname{curl}_{z} \tau$ is the wind stress curl computed from QuikSCAT gridded daily wind.

Figure 22a shows the temporal variation of each term in the vorticity balance equation averaged over the same 
a)

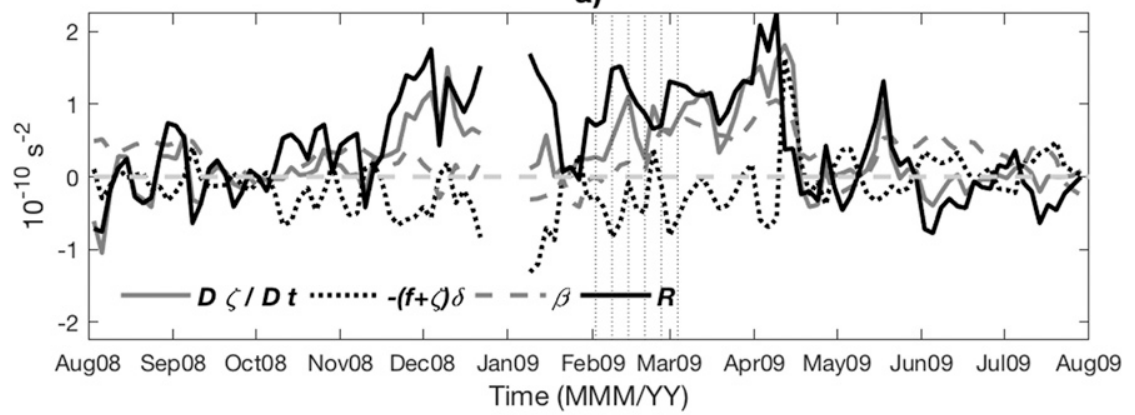

b)

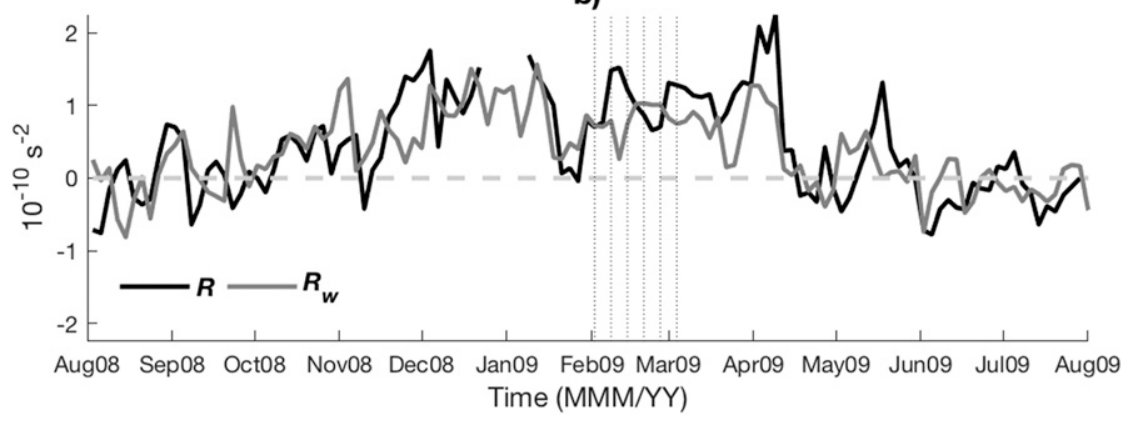

FIG. 22. (a) Time series of surface ocean vorticity balance terms averaged over the specified region (box in Fig. 17). The $\beta$ term is multiplied by 10. (b) Residual term $R$ and wind stress contribution to the residual term $R_{w}$. Vertical dotted lines indicate the snapshots in Figs. 23 and 24.

box in Fig. 17. Note that the $\beta$ term is magnified by a factor of 10 to show the trend. The evolution of the vorticity within the vortex core was generally dominated by frictional processes $R$ which drives the formation of cyclonic vorticity from mid-November until mid-April. Correlation between $D \xi / D t$ and $R$ is 0.79 . Observe, however, a significant lag of about 6 days between the two terms during the NE monsoon, specifically during strengthening of the cyclonic eddy during December 2008, February 2009, and April 2009. The $R_{w}$ from QuikSCAT compares well with the $R$ from the HFDR observations, suggesting that the frictional forcing $R$ is induced dominantly by the wind stress curl driving the cyclonic vorticity evolution after a time lag of about 6 days (Fig. 22b).

Another interesting finding involves the $\beta$ term. Recall the westward considerable shift of the eddy (Fig. 11) during the waning NE monsoon. Figure 22a shows that the shift coincides with an increasing $\beta$, though an order of magnitude less than the other terms. We speculate that the $\beta$ term causes the cyclonic eddy to propagate westward in the manner of a Rossby wave.

Figures 23 and 24 show the spatial distribution on six different days of each term of the vorticity balance taken within the RIOP-09 period. If the Lagrangian rate of change of vorticity is caused by frictional forcing, their spatial distribution should be comparable. But since there is a considerable time lag between the two terms (Fig. 22), disparity on their spatial variability notably exists. The westward-propagating eddy, on the other hand, is consistent with the increasing $\beta$ term.

\section{TIME LAG BETWEEN THE WIND FORCING AND THE OCEAN RESPONSE}

To clarify the relationship between the cyclonic eddy-formation processes and the wind stress curl forcing (correlation shown in Fig. 21), temporal variability of divergence $\delta$ and relative vorticity $\zeta$ were plotted against the Ekman pumping velocity $w_{E} / H_{E}$ proportional to wind stress curl (Fig. 25). Since a higher correlation exists between divergence and the Ekman pumping velocity (Fig. 21, left), Fig. 25 (top) specifically shows that it occurs during strong and persistent NE monsoon winds, although peaks and dips occur because of the shifts of the eddy. In contrast, vorticity increases quickly with progressing NE monsoon winds resulting in a relatively higher RMS diff $=0.18$ compared to divergence with RMS diff $=0.03$ (Fig. 25, bottom). The Ekman pumping velocity is positive during October when the NE monsoon prevails; however, the response of the ocean to changes in the wind stress curl is not instantaneous. The cyclonic vortex first appears as a closed circulation in the low-frequency current field only in mid-November, indicated by positive 

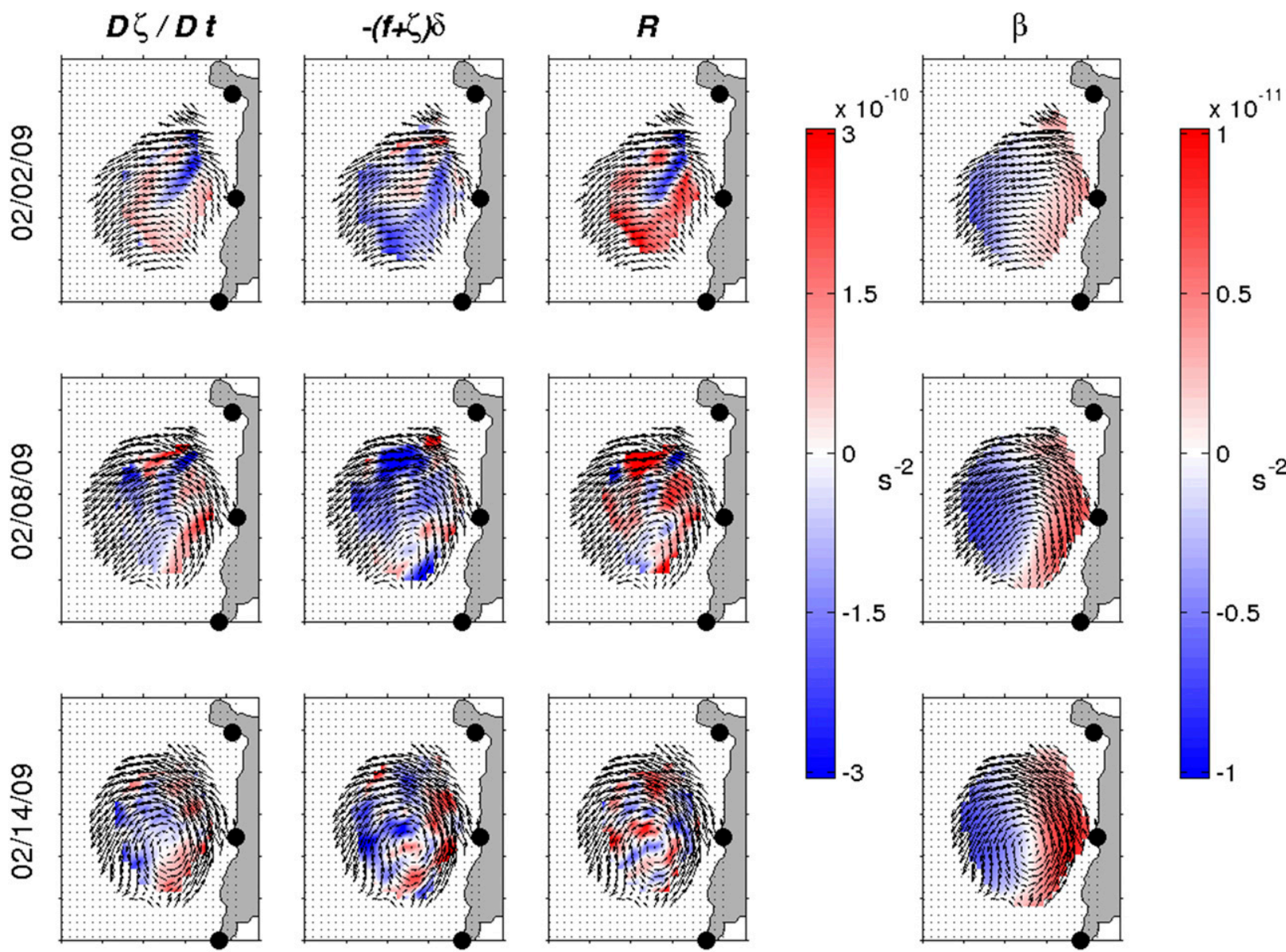

FIG. 23. Snapshots of the terms of the surface ocean vorticity balance [Eq. (3)], overlaid with surface currents. From left to right, Lagrangian rate of change of vorticity $D \zeta / D t$, vortex stretching $(f+\zeta) \delta$, residual $R$, and beta-effect $\beta$ terms. The times of snapshots are indicated on the $y$ axis of the first column.

vorticity $(0.05 f)$, and attained its maximum in February $2009(0.61 f)$.

To further examine the time-lag response of cyclonic eddy generation, the temporal variation of thermocline depth anomaly is compared with the time integrals of the Ekman pumping velocity and divergence. The best fit between the two terms was found at Ekman depth $H_{E}=32 \mathrm{~m}$ and used as constant for all calculations.

The time integrals of the Ekman pumping velocity and divergence from a reference time (28 July 2008) represent their cumulative effect on the vorticity evolution, provided that internal and external drags are neglected. The thermocline depth anomaly, on the other hand, is proportional to vorticity, assuming a geostrophic balance in a 1.5-layer reduced gravity model,

$$
\begin{array}{r}
f u=-g^{\prime} \frac{\partial h}{\partial y}, \\
-f v=-g^{\prime} \frac{\partial h}{\partial x},
\end{array}
$$

where $x$ and $y$ are the conventional Cartesian coordinates, $u$ and $v$ the horizontal components of velocity, $f$ the Coriolis parameter, $g^{\prime}=g \nabla \rho / \rho_{b}$ the reduced gravity ( $g$ is gravity $=9.8 \mathrm{~m} \mathrm{~s}^{-2}, \rho_{b}$ is the density at the motionless bottom layer, and $\nabla \rho$ is the density difference between the active top and motionless bottom layer), and $h(x, y)$ the thermocline depth anomaly.

Equations (5) were differentiated to obtain the relative vorticity and after some arranging, yields

$$
\begin{aligned}
f\left(\frac{\partial v}{\partial x}-\frac{\partial u}{\partial y}\right) & =-g^{\prime} \nabla^{2} h, \quad \text { and } \\
\zeta & =\frac{-g^{\prime} \nabla^{2} h}{f} .
\end{aligned}
$$

The cyclonic eddy is assumed to be radially symmetric with sea surface height $h$ perturbation at radial distance $r$ from the center of the eddy that has a Gaussian structure of the form 

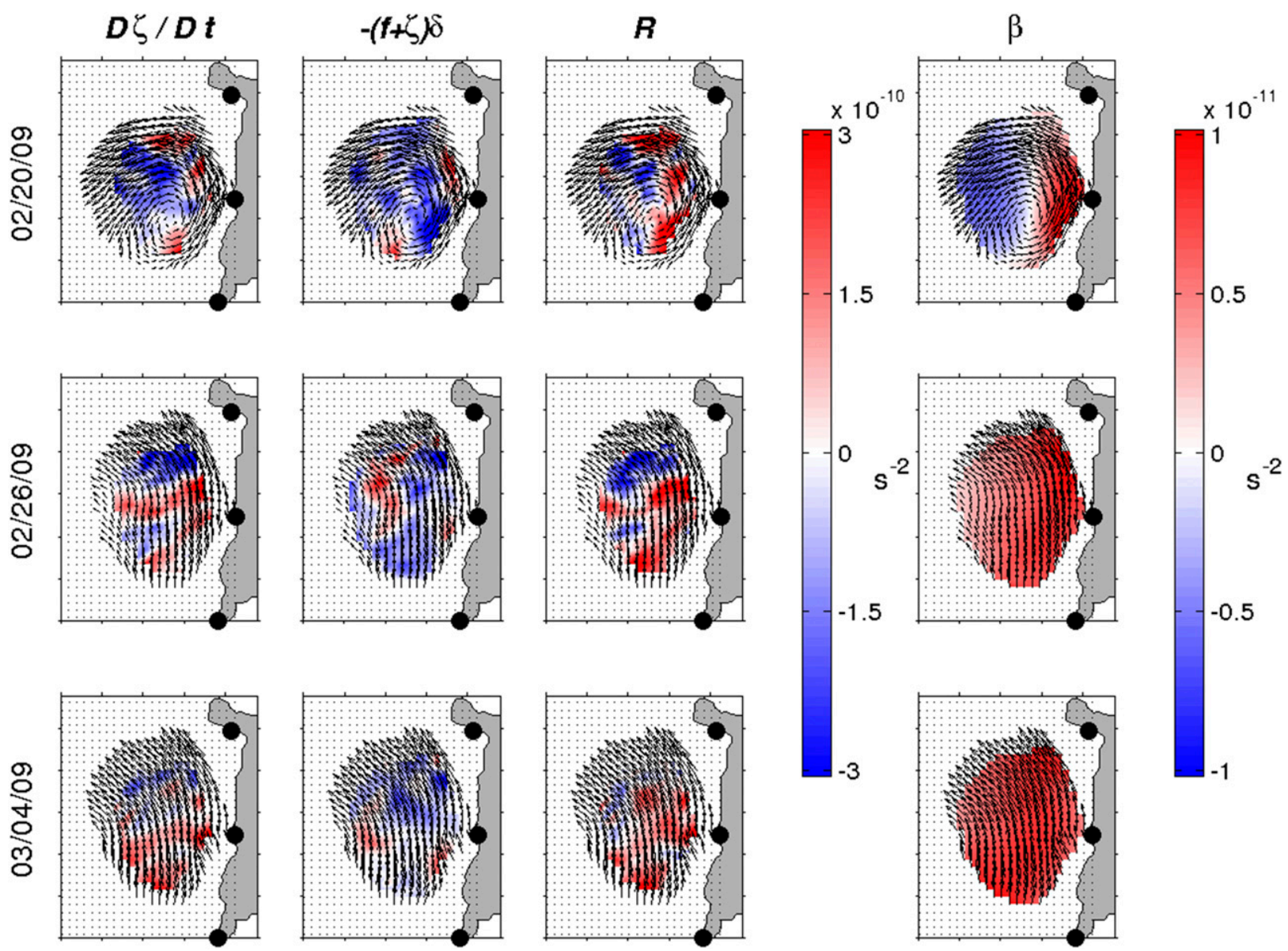

FIG. 24. Snapshots of the terms of the surface ocean vorticity balance [Eq. (3)], overlaid with surface currents. From left to right, Lagrangian rate of change of vorticity $D \zeta / D t$, vortex stretching $(f+\zeta) \delta$, residual $R$, and beta-effect $\beta$ terms. The times of snapshots are indicated on the $y$ axis of the first column.

$$
h(r)=h_{0} \exp \left(-\frac{r^{2}}{L^{2}}\right)
$$

where $h_{0}$ is the amplitude of the eddy, and $L$ is the radius of the eddy. This height function was substituted into Eq. (7) to give

$$
h=\frac{\zeta f L^{2}}{g^{\prime}}
$$

where $L$ and $g^{\prime}$ were estimated from the mean hydrographic cross-shore section, while corresponding vorticity $\zeta$ was calculated from HFDR.

Figure 26 shows that the Ekman divergence is an instantaneous response to the positive wind stress curl forcing. When the NE monsoon prevails, after a quick transition period in October (Fig. 8), the integrated wind stress curl becomes positive. Consequently, divergence occurs and increases rapidly along with the wind stress curl from mid-October 2008 until mid-April 2009. After the transition period in April 2009, the wind stress curl becomes very weak with no further increase in the time integral. In contrast, convergence occurs during the SW monsoon period as the region is now dominated by the northward PC jet, resulting in relatively higher sea level and warmer temperature evident from the bottom pressure gauges' measurements deployed during the same monsoon regime in Pandan (Fig. 27). The consequences of divergence/convergence and the influence of island topography on the surface dynamics were explained by Solera (2012). During the SW monsoon, divergence was not readily observed, and the higher positive sea level anomaly observed in Pandan was associated by the presence of the headland at the northern tip of Panay Island, which blocks further flow northward, causing a greater pileup of water at the corner of the promontory. Further, SW monsoon winds lead to onshore Ekman drift, causing a pileup of water at the coast, hence the positive sea level anomaly was observed.

Correspondingly, a time-lag response in the vorticity field occurs a month after mid-November 2009 (Fig. 26) 

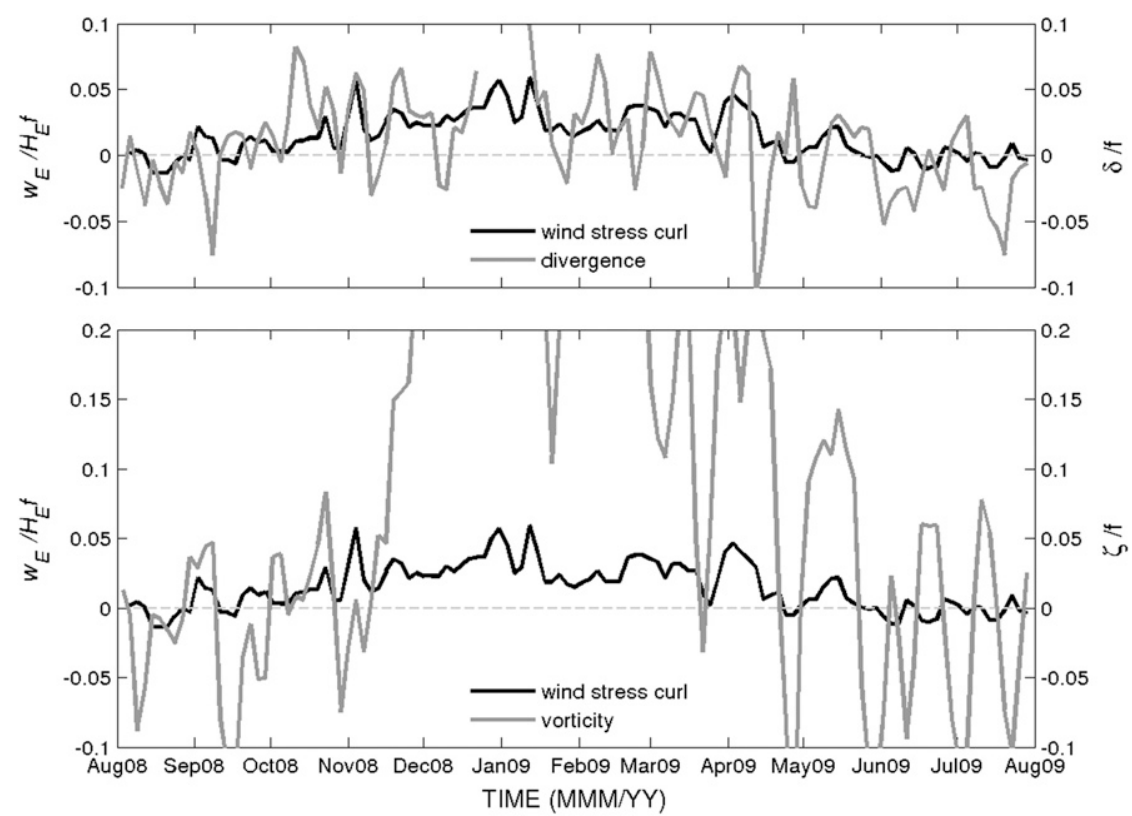

FIG. 25. Time series of surface ocean (top) divergence and (bottom) relative vorticity with wind stress curl. All terms were normalized by $f$.

when it increases quickly, producing a mature and closed cyclonic eddy circulation shown in Fig. 10 (bottom). The current vorticity reaches its maximum in January 2009, though HFDR data are missing but can be inferred from the increasing values of vorticity and the strength of wind reaching its maximum during this time of the year (Fig. 8). After that initial period, ocean vorticity responds effectively to fluctuating local wind magnitude and direction where peaks and dips correspond with the strong and weak NE monsoon wind, respectively. A considerable decrease of vorticity value in March 2009 indicates the westward shift of the center of the eddy in March 2009, though the cumulative wind stress curl and divergence are still proportionally increasing. This further supports the $\beta$ term causing the cyclonic eddy to propagate westward. This relevance of the $\beta$ term has been known in many geophysical fluid phenomena, like in the global observations of large oceanic eddies propagating nearly westward explained in terms of the westward propagation of Rossby waves (Chelton et al. 2007).

\section{Summary and conclusions}

High-resolution observations both in time and space of surface currents resolved the details of the low-frequency mesoscale flow in Panay Strait. The surface circulation

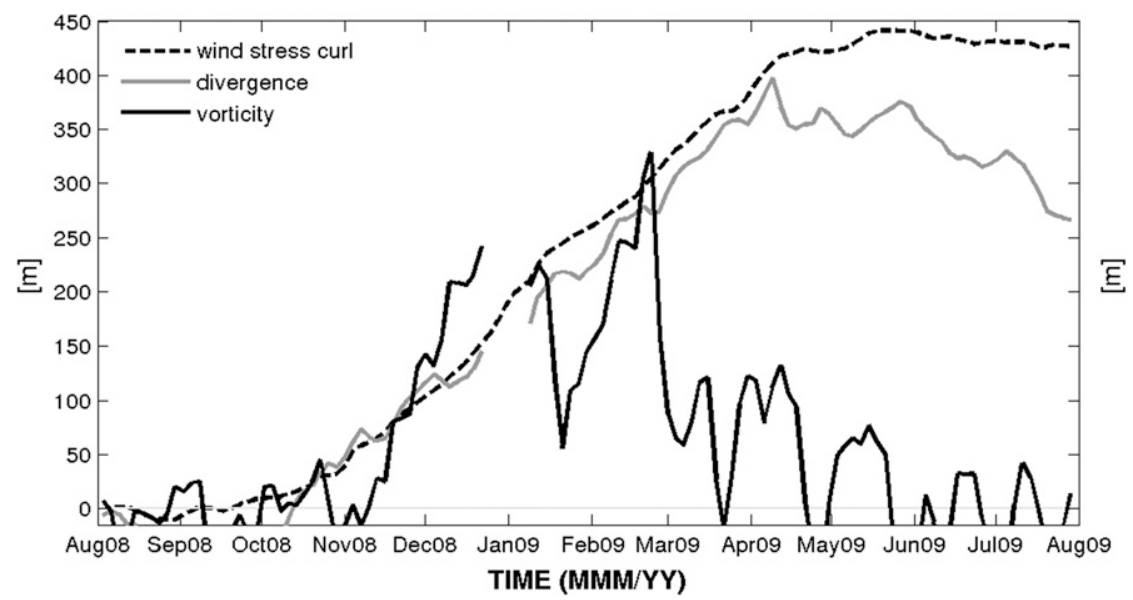

FIG. 26. Surface ocean vorticity overlaid with time integral of wind stress curl and surface ocean divergence confined within the Ekman layer $\left(H_{E}=32 \mathrm{~m}\right)$. 

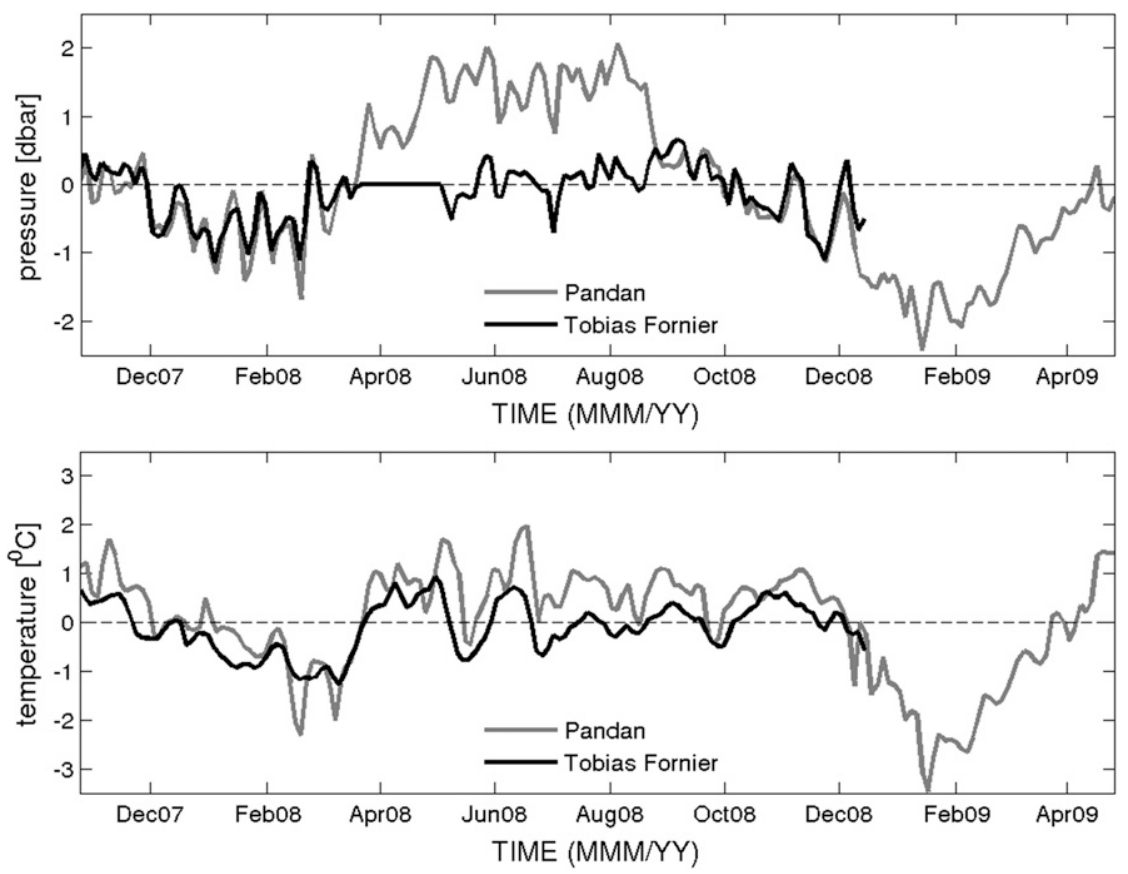

FIG. 27. Time-series (top) sea level and (bottom) temperature anomaly from Pandan and Tobias Fornier shallow pressure gauges.

in the strait has a distinctly seasonal cycle with the generation of a cyclonic eddy during the NE monsoon, reinforcing the steady PC jet as its eastern limb.

It also provides the most detailed mechanism of eddy generation and evolution due to Ekman pumping without a strong oceanic flow passing the island. The seasonal evolution of the cyclonic eddy is an oceanic response to the prevailing local wind. The strong wind jets through the Tablas Strait, in between Mindoro and Panay and a calm lee, generate a positive wind stress curl during the $\mathrm{NE}$ monsoon. Based on observations and satellite-derived winds, wind curl field variations due to the changes in the strength and direction of the prevailing local wind play an important role in the generation and evolution of the eddy and variability of the PC jet in the lee of Panay.

The region of positive wind stress curl causes Ekman flux divergence in the upper layer, which in turn drives Ekman pumping, lifting the thermocline and stretching the water column beneath, forming the Panay Dome. This results in horizontal pressure gradients, which consequently generates a cyclonic eddy in geostrophic balance. The Panay Dome is a subsurface upwelling, west of the shallow Cuyo Shelf, characterized by a vertically mixed water column, which destroys the water column stratification and therefore leads to enhanced biological productivity over the region.

Evaluating all the terms of the surface vorticity balance equation suggests that the wind stress curl via
Ekman pumping mechanism provides the necessary input in the formation and evolution of the cyclonic eddy. The beta effect, on the other hand, may lead to propagation of the eddy westward.

In particular, the cumulative (time integrated) effect of the wind stress curl plays a key role on the generation of the cyclonic eddy, showing its robust mechanism to eddy kinetic energy. Further, this study shows that unlike divergence, vorticity response to prevailing wind stress curl is not instantaneous, causing a time lag, which may help toward understanding the physical development of coastal upwelling due to Ekman pumping in the lee of the island.

Acknowledgments. To the dedication and skill of the captain and crew of the R/V Melville and the many U.S. and Philippine students, technicians, volunteers, and scientists who participated, assisted, and helped in the cruises and fieldwork in Antique, Philippines. Local government units and people of municipalities of Pandan, Tobias Fornier, and Laua-an, Antique, for their full support and assistance. We are indebted to the landowners, the late Enrique A. Zaldivar of Pandan; Erlinda B. Montero of Laua-an; Maria A. Moscoso, represented by her son Ramon A. Moscoso Jr.; Ernesto P. Near; and Ronelia Tingocia of Tobias Fornier for their kindness and hospitality. The three anonymous reviewers for their constructive comments and suggestions that significantly 
helped improve the manuscript. This work was funded by the Office of the Naval Research (ONR) through the Philippine Strait Dynamics Experiment (PhilEx) program, under Award N00014-09-1-0807 to Pierre J. Flament, University of Hawaii, Award and Subaward N00014-06-10686 to Pierre J. Flament of the University of Hawaii and Cesar Villanoy of the University of the Philippines. The authors thank Janet Sprintal for providing the moored shallow pressure gauges and ADCP data (N00014-061-690); Craig Lee for sharing the TRIAXUS data (N00014-06-1-0687); NOAA/NESDIS/ORA/STAR and Christopher Jackson, Global Ocean Associates, for providing the ASAR image in Fig. 15; Robert Arnone and Sherwin Ladner for providing satellite images in Figs. 19 and 20; and Julie Pullen, Paul May, and James Doyle for the model winds from their Philippine archipelago COAMPS model (N00014-10-1-0300). COAMPS is a registered trademark of the Naval Research Laboratory. This paper is School of Ocean and Earth Science and Technology Contribution Number 10631.

\section{REFERENCES}

Arango, H. G., and Coauthors, 2011: Development of a hindcast/ forecast model for the Philippine archipelago. Oceanography, 24 (1), 58-69, https://doi.org/10.5670/oceanog.2011.04.

Azevedo Correia de Souza, J. M., B. Powell, A. C. Castillo-Trujillo, and P. Flament, 2015: The vorticity balance of the ocean surface in Hawaii from a regional reanalysis. J. Phys. Oceanogr., 45, 424-440, https://doi.org/10.1175/JPO-D-14-0074.1.

Barton, E. D., and Coauthors, 1993: Supersquirt: Dynamics of the Gulf of Tehuantepec, Mexico. Oceanography, 6 (1), 23-30, https://doi.org/10.5670/oceanog.1993.19.

_ G. Gasterretxea, P. Flament, E. G. Mitchelson-Jacob, B. Jones, J. Arístegui, and F. Herrera, 2000: Lee region of Gran Canaria. J. Geophys. Res., 105, 17173-17193, https://doi.org/10.1029/ 2000JC900010.

Caldeira, R. M. A., A. Stegner, X. Couvelard, I. B. Araújo, P. Testor, and A. Lorenzo, 2014: Evolution of an oceanic anticyclone in the lee of Madeira Island: In situ and remote sensing survey. J. Geophys. Res. Oceans, 119, 1195-1216, https://doi.org/10.1002/2013JC009493.

Calil, P. H., K. J. Richards, Y. Jia, and R. R. Bidigare, 2008: Eddy activity in the lee of the Hawaiian Islands. Deep-Sea Res. II, 55, 1179-1194, https://doi.org/10.1016/j.dsr2.2008.01.008.

Chang, C.-P., Z. Wang, and H. Hendon, 2006: The Asian winter monsoon. The Asian Monsoon, Springer, 89-127.

Chapman, R. D., L. K. Shay, H. C. Graber, J. B. Edson, A. Karachintsev, C. L. Trump, and D. B. Ross, 1997: On the accuracy of HF radar surface current measurements: Intercomparisons with ship-based sensors. J. Geophys. Res., 102, 18 737-18 748, https://doi.org/10.1029/97JC00049.

Chavanne, C., P. Flament, R. Lumpkin, B. Dousset, and A. Bentamy, 2002: Scatterometer observations of wind variations induced by oceanic islands: Implications for wind-driven ocean circulation. Can. J. Remote Sens., 28, 466-474, https://doi.org/10.5589/m02-047. , I. Janeković, P. Flament, P.-M. Poulain, M. Kuzmić, and K.-W. Gurgel, 2007: Tidal currents in the northwestern Adriatic: High-frequency radio observations and numerical model predictions. J. Geophys. Res., 112, C03\$21, https://doi.org/ 10.1029/2006JC003523.

Chelton, D. B., M. G. Schlax, R. M. Samelson, and R. A. de Szoeke, 2007: Global observations of large oceanic eddies. Geophys. Res. Lett., 34, L15606, https://doi.org/10.1029/2007GL030812.

Chen, T.-C., and S.-P. Weng, 1996: Some effects of the intraseasonal oscillation on the equatorial waves over the western tropical Pacific-South China Sea region during the northern summer. Mon. Wea. Rev., 124, 751-756, https://doi.org/ 10.1175/1520-0493(1996)124<0751:SEOTIO > 2.0.CO;2.

Dong, C., and Coauthors, 2009: An oceanic cyclonic eddy on the lee side of Lanai Island, Hawai'i. J. Geophys. Res., 114, C10008, https://doi.org/10.1029/2009JC005346.

Gaberšek, S., and D. R. Durran, 2004: Gap flows through idealized topography. Part I: Forcing by large-scale winds in the nonrotating limit. J. Atmos. Sci., 61, 2846-2862, https://doi.org/ 10.1175/JAS-3340.1.

- and — 2006: Gap flows through idealized topography. Part II: Effects of rotation and surface friction. J. Atmos. Sci., 63, 2720-2739, https://doi.org/10.1175/JAS3786.1.

Gill, A. E., 1982: Atmosphere-Ocean Dynamics. Academic Press, $662 \mathrm{pp}$.

Gordon, A. L., and C. L. Villanoy, 2011: The oceanography of the Philippine archipelago. Oceanography, 24 (1), 13, https://doi.org/ 10.5670/oceanog.2011.13.

Han, W., and Coauthors, 2009: Seasonal surface ocean circulation and dynamics in the Philippine archipelago region during 2004-2008. Dyn. Atmos. Oceans, 47, 114-137, https://doi.org/ 10.1016/j.dynatmoce.2008.10.007.

Jia, Y., P. H. R. Calil, E. P. Chassignet, E. J. Metzger, J. T. Potemra, K. J. Richards, and A. J. Wallcraft, 2011: Generation of mesoscale eddies in the lee of the Hawaiian Islands. J. Geophys. Res., 116, C11009, https://doi.org/10.1029/2011JC007305.

Jiménez, B., P. Sangrà, and E. Mason, 2008: A numerical study of the relative importance of wind and topographic forcing on oceanic eddy shedding by tall, deep water islands. Ocean Modell., 22 , 146-157, https://doi.org/10.1016/j.ocemod.2008.02.004.

Kersalé, M., A. M. Doglioli, and A. A. Petrenko, 2011: Sensitivity study of the generation of mesoscale eddies in a numerical model of Hawaii Islands. Ocean Sci., 7, 277-291, https://doi.org/ 10.5194/os-7-277-2011.

Lumpkin, C., 1998: Eddies and currents of the Hawaiian Islands. Ph.D. thesis, University of Hawai'i at Mānoa, 282 pp.

May, P. W., J. D. Doyle, J. D. Pullen, and L. T. David, 2011: Twoway coupled atmosphere-ocean modeling of the PhilEx intensive observational periods. Oceanography, 24 (1), 48-57, https://doi.org/10.5670/oceanog.2011.03.

McClean, J. L., D. P. Ivanova, and J. Sprintall, 2005: Remote origins of interannual variability in the Indonesian Throughflow region from data and a global parallel ocean program simulation. J. Geophys. Res., 110, C10013, https://doi.org/10.1029/ 2004JC002477.

Pawlowicz, R., B. Beardsley, and S. Lentz, 2002: Classical tidal harmonic analysis including error estimates in MATLAB using T_TIDE. Comput. Geosci., 28, 929-937, https://doi.org/ 10.1016/S0098-3004(02)00013-4.

Piedeleu, M., P. Sangrà, A. Sánchez-Vidal, J. Fabrés, C. Gordo, and A. Calafat, 2009: An observational study of oceanic eddy generation mechanisms by tall deep-water islands (Gran Canaria). Geophys. Res. Lett., 36, L14605, https://doi.org/ 10.1029/2008GL037010.

Pullen, J., J. D. Doyle, P. May, C. Chavanne, P. Flament, and R. A. Arnone, 2008: Monsoon surges trigger oceanic eddy formation 
and propagation in the lee of the Philippine Islands. Geophys. Res. Lett., 35, L07604, https://doi.org/10.1029/2007GL033109.

- , A. L. Gordon, J. Sprintall, C. M. Lee, M. H. Alford, J. D. Doyle, and P. W. May, 2011: Atmospheric and oceanic processes in the vicinity of an island strait. Oceanography, 24 (1), 112-121, https:// doi.org/10.5670/oceanog.2011.08.

Rypina, I. I., L. J. Pratt, J. Pullen, J. Levin, and A. L. Gordon, 2010: Chaotic advection in an archipelago. J. Phys. Oceanogr., 40, 1988-2006, https://doi.org/10.1175/2010JPO4336.1.

Sangrà, P., and Coauthors, 2009: The Canary Eddy Corridor: A major pathway for long-lived eddies in the subtropical North Atlantic. Deep-Sea Res. I, 56, 2100-2114, https://doi.org/ 10.1016/j.dsr.2009.08.008

Solera, L., 2012: Sea level variability and surface dynamics in the interior of the Philippine archipelago. M.S thesis, Marine Science Institute, University of the Philippines, $83 \mathrm{pp}$.

Sprintall, J., A. L. Gordon, P. Flament, and C. L. Villanoy, 2012: Observations of exchange between the South China Sea and the Sulu Sea. J. Geophys. Res., 117, C05036, https://doi.org/ 10.1029/2011JC007610.

Thompson, D. R., and R. C. Beal, 2000: Mapping high-resolution wind fields using synthetic aperture radar. Johns Hopkins APL Tech. Dig., 21, 58-67.

Trasviña, A., E. D. Barton, J. Brown, H. S. Velez, P. M. Kosro, and R. L. Smith, 1995: Offshore wind forcing in the Gulf of Tehuantepec, Mexico: The asymmetric circulation. J. Geophys. Res., 100, 20 649-20 663, https://doi.org/10.1029/95JC01283.

Wang, B., R. Wu, and K.-M. Lau, 2001: Interannual variability of the Asian summer monsoon: Contrasts between the Indian and the western North Pacific-East Asian monsoons. J. Climate, 14, 4073-4090, https://doi.org/10.1175/1520-0442(2001)014<4073: IVOTAS $>2.0 . \mathrm{CO} ; 2$.
Wang, G., J. Su, and P. C. Chu, 2003: Mesoscale eddies in the South China Sea observed with altimeter data. Geophys. Res. Lett., 30, 2121, https://doi.org/10.1029/2003GL018532.

- D. Chen, and J. Su, 2008: Winter eddy genesis in the eastern South China Sea due to orographic wind jets. J. Phys. Oceanogr., 38, 726-732, https://doi.org/10.1175/2007JPO3868.1.

Wang, J., Y. Qi, and I. S. F. Jones, 2006: An analysis of the characteristics of chlorophyll in the Sulu Sea. J. Mar. Syst., 59, 111119, https://doi.org/10.1016/j.jmarsys.2005.09.004.

Weber, R. O., and P. Kaufmann, 1998: Relationship of synoptic winds and complex terrain flows during the mistral field experiment. J. Appl. Meteor., 37, 1486-1496, https://doi.org/ 10.1175/1520-0450(1998)037<1486:ROSWAC $>2.0 . C O ; 2$.

Webster, P. J., V. O. Magaña, T. N. Palmer, J. Shukla, R. A. Tomas, M. Yanai, and T. Yasunari, 1998: Monsoons: Processes, predictability, and the prospects for prediction. J. Geophys. Res., 103, 14 451-14 510, https://doi.org/10.1029/97JC02719.

White, W. B., Y. M. Tourre, M. Barlow, and M. Dettinger, 2003: A delayed action oscillator shared by biennial, interannual, and decadal signals in the Pacific basin. J. Geophys. Res., 108, 3070, https://doi.org/10.1029/2002JC001490.

Whiteman, C. D., and J. C. Doran, 1993: The relationship between overlying synoptic-scale flows and winds within a valley. J. Appl. Meteor., 32, 1669-1682, https://doi.org/10.1175/15200450(1993)032<1669:TRBOSS > 2.0.CO;2.

Wu, M. C., and J. C. L. Chan, 1995: Surface features of winter monsoon surges over South China. Mon. Wea. Rev., 123, 662-680, https://doi.org/10.1175/1520-0493(1995)123<0662: SFOWMS $>2.0 . \mathrm{CO} ; 2$.

Yoshida, S., B. Qiu, and P. Hacker, 2010: Wind-generated eddy characteristics in the lee of the island of Hawaii. J. Geophys. Res., 115, C03019, https://doi.org/10.1029/2009JC005417. 